\title{
On Different Microphysical Pathways to Convective Rainfall
}

\author{
SONIA LASHER-TraPP, SHAILENDRA KUMAR, ${ }^{\mathrm{a}}$ AND DANIEL H. MOSER ${ }^{\mathrm{b}}$ \\ Department of Atmospheric Sciences, University of Illinois at Urbana-Champaign, Urbana, Illinois
}

\begin{abstract}
ALAN M. BLYTH
National Centre for Atmospheric Science, Institute of Climate and Atmospheric Science, University of Leeds, Leeds, United Kingdom

\author{
JefFrey R. French, Robert C. JACKson, ${ }^{\mathrm{c}}$ DAVID C. LeOn, ${ }^{\mathrm{d}}$ AND DAVID M. Plummer \\ Department of Atmospheric Science, University of Wyoming, Laramie, Wyoming
}

(Manuscript received 12 February 2018, in final form 21 July 2018)

\begin{abstract}
The Convective Precipitation Experiment (COPE) documented the dynamical and microphysical evolution of convection in southwestern England for testing and improving quantitative precipitation forecasting. A strong warm rain process was hypothesized to produce graupel quickly, initiating ice production by rime splintering earlier to increase graupel production and, ultimately, produce heavy rainfall. Here, convection observed on two subsequent days (2 and 3 August 2013) is used to test this hypothesis and illustrate how environmental factors may alter the microphysical progression. The vertical wind shear and cloud droplet number concentrations on 2 August were 2 times those observed on 3 August. Convection on both days produced comparable maximum radar-estimated rain rates, but in situ microphysical measurements indicated much less ice in the clouds on 2 August, despite having maximum cloud tops that were nearly $2 \mathrm{~km}$ higher than on 3 August. Idealized 3D numerical simulations of the convection in their respective environments suggest that the relative importance of particular microphysical processes differed. Higher (lower) cloud droplet number concentrations slow (accelerate) the warm rain process as expected, which in turn slows (accelerates) graupel formation. Rime splintering can explain the abundance of ice observed on 3 August, but it was hampered by strong vertical wind shear on 2 August. In the model, the additional ice produced by rime splintering was ineffective in enhancing surface rainfall; strong updrafts on both days lofted supercooled raindrops well above the $0^{\circ} \mathrm{C}$ level where they froze to become graupel. The results illustrate the complexity of dynamical-microphysical interactions in producing convective rainfall and highlight unresolved issues in understanding and modeling the competing microphysical processes.
\end{abstract}

\section{Introduction and motivation}

The Convective Precipitation Experiment (COPE) was held in July and August of 2013 in southwestern England to collect data on the dynamics and microphysics of convective precipitation that could lead to

\footnotetext{
${ }^{\text {a }}$ Current affiliation: Peru Institute of Geophysics, Lima, Peru.

${ }^{\mathrm{b}}$ Current affiliation: Lyda Hill Dept. of Bioinformatics, University of Texas Southwest Medical Center, Dallas, Texas.

${ }^{\mathrm{c}}$ Current affiliation: Argonne National Laboratory, Argonne, Illinois.

${ }^{\mathrm{d}}$ Current affiliation: Alpenglow Instruments, Laramie, Wyoming.
}

\footnotetext{
Corresponding author: Dr. Sonia Lasher-Trapp, slasher@illinois. edu
}

improvements in the numerical prediction of heavy rainfall events (i.e., rain rates exceeding $25 \mathrm{~mm} \mathrm{~h}^{-1}$ ). This region of England has a history of experiencing flash flood events (including recent events in summer 2017) in which nearly stationary lines of heavily precipitating convection can develop (e.g., Golding et al. 2005). Several research aircraft and a portable groundbased radar, along with a wind profiler and surface aerosol measurement site, were deployed. A variety of numerical weather prediction models were run by the Met Office. A detailed description of the field project and highlights of some cases are provided by Leon et al. (2016).

One of the specific goals of COPE was to learn what "microphysical pathway(s)" can promote heavy convective 
rainfall. In mixed-phase convection, multiple pathways to heavy rainfall exist that can be broadly classified as

1) condensation followed by collision-coalescence into raindrops that fall to the ground without any important role of the ice phase (i.e., the warm rain process),

2) suspension of raindrops produced by the warm rain process within the updraft, lofted to lower temperatures where they are converted to graupel either by immersion freezing or collision with primary nucleated ice, the graupel further growing by riming (of cloud water or collection of supercooled raindrops) and ultimately falling and melting to produce surface rainfall, and

3) the pathway in class 2 but leading to the generation of secondary ice particles (e.g., rime splintering by falling graupel, or shattering of freezing raindrops) that themselves accrete supercooled cloud droplets to produce graupel and ultimately surface rainfall.

A working hypotheses of COPE was that the microphysical pathway specified in class 3 is important for heavy rainfall produced by warm-based convection with low cloud droplet concentrations. The COPE observations were consistent with this hypothesized microphysical progression. The cloud condensation nuclei $(\mathrm{CCN})$ in the local air (ranging from 100 to $500 \mathrm{~cm}^{-3}$ at $0.9 \%$ supersaturation), as well as prevalent giant and ultragiant aerosol particles (Taylor et al. 2016a) did often result in a productive warm rain process in the stronger convection (Leon et al. 2016). Supercooled raindrops were often observed in the updrafts by radar and aircraft (Plummer et al. 2018; Jackson et al. 2018). Although quantification of icenucleating particles from aircraft measurements was not available, in situ aircraft measurements frequently showed ice number concentrations exceeding hundreds per liter, far greater than the number of icenucleating particles typically active at the sampling temperatures (from $0^{\circ}$ to $-14^{\circ} \mathrm{C}$ ). Rime splintering was implicated as a source of these large numbers of ice crystals in some cases (Taylor et al. 2016b; Jackson et al. 2018).

However, determining the dominant microphysical pathway is very difficult from the observations alone. Researchers conducting weather modification activities understood the potential importance of increasing the number of graupel to enhance convective rainfall, and also noted from their observational analyses that raindrops forming from the warm rain process appeared to have some role in the generation of secondary ice (e.g., Koenig 1963; Braham 1964; Chisnell and
Latham 1976; Hallett et al. 1978). At that time, the computational abilities required to simulate the 3D cloud dynamics and microphysics to follow the progression to rainfall were lacking. Various modeling studies since that era have suggested that the warm rain process is important in producing supercooled raindrops that freeze and rime and initiate rime splintering (e.g., Ovtchinnikov and Kogan 2000; Phillips et al. 2001; Huang et al. 2008; Sun et al. 2010), but these studies have been limited by modeling simplifications (2D) or a less comprehensive set of observational data for comparison.

Here, high-resolution (150-m grid spacing in the $x, y$, and $z$ directions), idealized 3D numerical simulations are employed to contrast potential differences in early precipitation development observed on two consecutive days sampled during the COPE field campaign. For these two days, different dependencies among the microphysical processes are investigated, and their possible relative contributions to surface rainfall are evaluated. The idealized nature of these simulations makes the utility of detailed, direct comparison with the radar or aircraft measurements of questionable value. Thus, the emphasis of this study is to reproduce the general microphysical trends observed on the two days, and then to explore the possible reasons for those trends in the model.

The numerical modeling performed here also allows an exploration of factors related to the cloud environment that can modulate the dominant microphysical pathway(s) to surface precipitation. The local static stability of the atmosphere controls the cloud depth and thus the temperature range over which it spans, as well as the buoyancy of parcels and thus updraft/downdraft strength. The buoyancy, updraft strength, and cloud depth can also be reduced by the entrainment of dry environmental air. The vertical wind shear affects cloud organization and structure, and thus affects particle trajectories that govern hydrometeor lifetime within the cloud, particle transport to favorable or unfavorable growth regions, cloud interactions, and cloud longevity. The aerosol characteristics of the local air mass also control microphysical processes through the number of $\mathrm{CCN}$ and ice-nucleating particles.

Precipitating convection observed over the southwestern England peninsula (cf. Fig. 9 in Leon et al. 2016) during COPE on 2 and 3 August 2013 had different environmental, dynamical, and microphysical characteristics. These cases provide a unique opportunity to investigate dynamical-microphysical interactions and specific microphysical pathways leading to heavy convective rainfall, over the same geographical area, and during the same season. 


\section{Overview of the 2 and 3 August cases observed during COPE}

From a thermodynamic perspective, the 2 August lowlevel environment was warmer and more unstable than that of 3 August (Fig. 1); surface-based CAPE values from the 1500 UTC COPE soundings were approximately 700 and $350 \mathrm{~J} \mathrm{~kg}^{-1}$, respectively, on the two days. Maximum cloud-top heights were near $8 \mathrm{~km}$ on 2 August versus $5-6 \mathrm{~km}$ on 3 August, the latter being limited by a stable layer located near $-14^{\circ} \mathrm{C}$ (Fig. 1). The 50th and 75 th percentiles of aircraft-sampled updraft speeds over similar temperature ranges were approximately 1 and $4 \mathrm{~ms}^{-1}$ greater on 2 August than on 3 August (Jackson et al. 2018).

The dynamical evolutions of the clouds on the two days were also somewhat different. At the time of aircraft sampling, shorter convective lines limited to a few cells formed and decayed on 2 August. ${ }^{1}$ A longer line (and sometimes two) on 3 August extended down the spine of the peninsula, formed and maintained by the convergence of opposing sea breezes. The sampled early 2 August convection contained cells that were spaced farther apart than those on 3 August. Radar data analysis suggests that successive thermals ascended within the paths of their predecessors on 3 August (Leon et al. 2016) and thus may have been somewhat shielded from the entrainment of dry environmental air (Moser and Lasher-Trapp 2017). Successive thermals, in which new turrets ascend through the remnant of earlier ones, would not have been favored on 2 August because of the much stronger environmental vertical wind shear on that day (Fig. 1). The 300-1000-hPa environmental vertical wind shear (from the 1500 UTC soundings) was 5 times as large on 2 August $\left(5 \times 10^{-3} \mathrm{~s}^{-1}\right)$ as on 3 August $\left(1 \times 10^{-3} \mathrm{~s}^{-1}\right)$. Wind shear over the respective cloud depths on the two days was $3 \times 10^{-3} \mathrm{~s}^{-1}$ and $4 \times 10^{-4} \mathrm{~s}^{-1}$, respectively; the deeper clouds on 2 August leaned much more with altitude.

Differences in microphysical development on the two days were also evident. Maximum cloud-base droplet number concentrations measured by the aircraft were $550-600 \mathrm{~cm}^{-3}$ on 2 August and $300-350 \mathrm{~cm}^{-3}$ on $3 \mathrm{Au}-$ gust. At comparable sampling temperatures within $1 \mathrm{~km}$ of cloud top, Jackson et al. (2018) found generally fewer hydrometeors exceeding $300-\mu \mathrm{m}$ diameter in the 2 August clouds than on 3 August, and often many fewer irregular particles indicative of ice. They also reported an abundance of ice crystals $\left(>100 \mathrm{~L}^{-1}\right)$ in the temperature range from $-3^{\circ}$ to $-8^{\circ} \mathrm{C}$ on 3 August, consistent with ice multiplication by the rime-splintering process. Similarly large

\footnotetext{
${ }^{1}$ After the period of aircraft sampling on 2 August, a much longer and persistent line of convection formed, oriented from south-southwest to north-northeast.
}

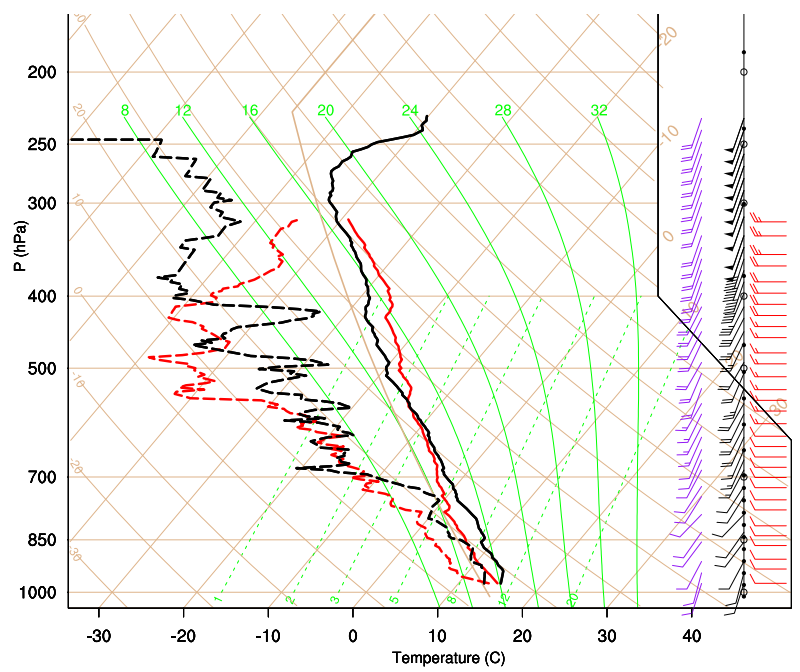

FIG. 1. Model "environment" conditions modified from atmospheric soundings released from Davidstow in southwestern England at 1500 UTC 2 Aug (black) and 1500 UTC 3 Aug 2013 (red). Also shown is the modified 2 August wind profile (purple) discussed in section $4 \mathrm{~d}$.

ice number concentrations, including columns, were reported by Taylor et al. (2016b) from in situ data collected by the BAE-146 aircraft sampling at lower altitudes within the clouds on 3 August. In contrast, columns in the particle image data on 2 August within the same temperature regime were rare.

Any or all of these environmental and microphysical factors may have contributed to the differences in precipitation produced by the convection on 2 and 3 August. Radar reflectivity maxima up to $60 \mathrm{~dB} Z$ were observed by the ground-based radar on both days, as well as columns of high values of differential reflectivity $Z_{\mathrm{DR}}{ }^{2}$ exceeding $3 \mathrm{~dB}$ (Plummer et al. 2018), indicative of large raindrops ascending within the updrafts. These $Z_{\mathrm{DR}}$ columns are suggestive of a strong warm rain process, often extending up to $1 \mathrm{~km}$ above the environmental $0^{\circ} \mathrm{C}$ isotherm. Instantaneous rain rates sometimes reached $60 \mathrm{~mm} \mathrm{~h}^{-1}$ (with a maximum of even $200 \mathrm{~mm} \mathrm{~h}^{-1}$ ), as estimated from the National Centre for Atmospheric Science mobile X-band dual-polarization Doppler weather radar (NXPol) data at $1.25 \mathrm{~km}$ AGL (Fig. 2) for both cases during the period of aircraft sampling. ${ }^{3}$ The intermittent nature of the higher

\footnotetext{
${ }^{2}$ The $Z_{\mathrm{DR}}$ is a ratio of horizontal to vertical backscattered radiation from the sensed hydrometeors, and increasingly positive values (beneath the $0^{\circ} \mathrm{C}$ isotherm) indicate oblate raindrops that are increasing in size.

${ }^{3}$ Rain gauge data, although sparsely distributed, indicated maximum rain rates up to $62 \mathrm{~mm} \mathrm{~h}^{-1}$ on 2 August but only to $20 \mathrm{~mm} \mathrm{~h}^{-1}$ on 3 August; however, the 3 August nearly stationary convective line was unfortunately located over regions lacking gauges.
} 

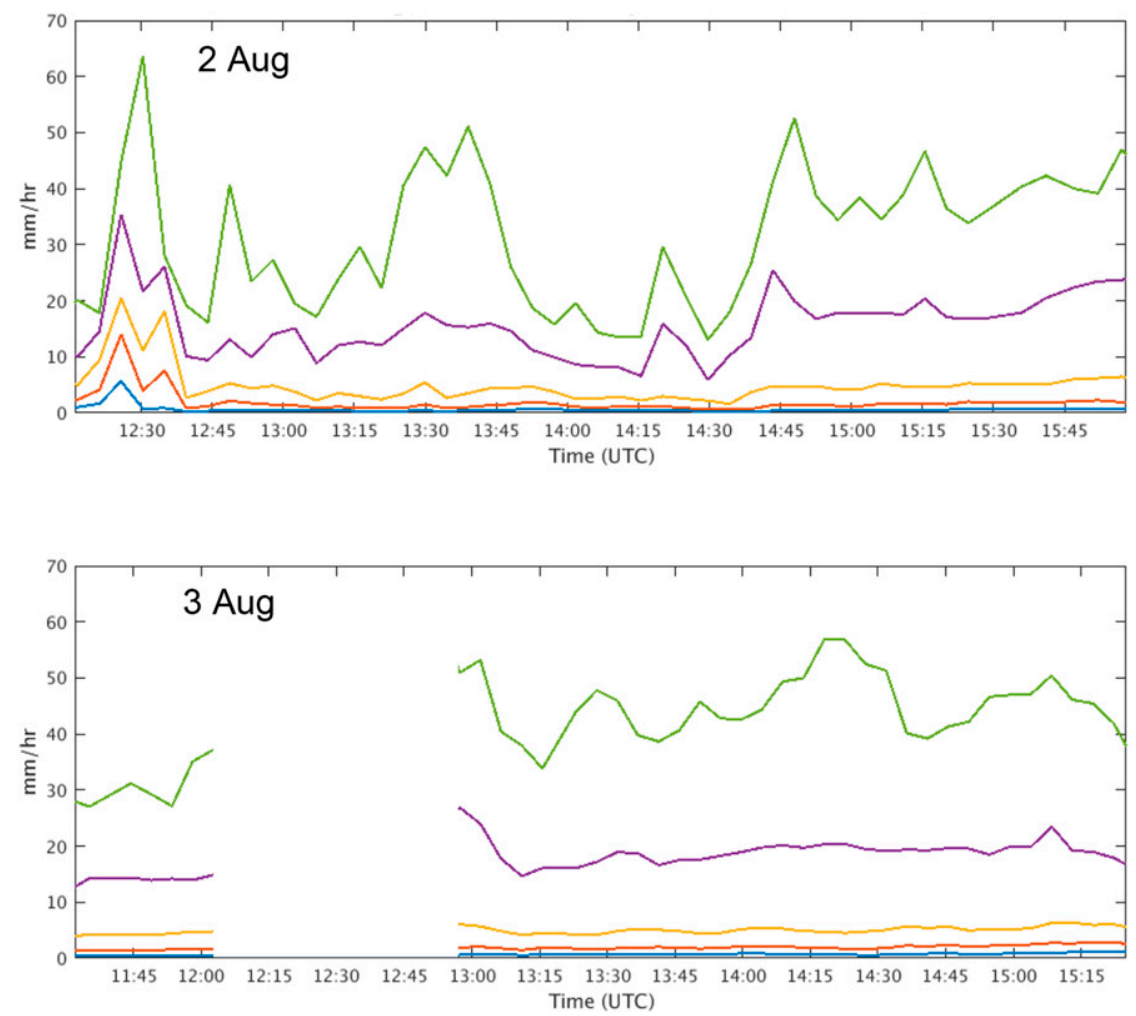

FIG. 2. Dual-polarization-radar-derived 5-min rainfall rates for (top) 2 Aug and (bottom) 3 Aug 2013 during the period of aircraft sampling, using data within a $60-\mathrm{km}$ range of the radar interpolated to a Cartesian grid at $1.25 \mathrm{~km}$ AGL. Curves indicate the 25th (blue), 50th (red), 75th (gold), 95th (purple), and 99th (green) percentile rain-rate values from individual scans at the times indicated. Radar data outage occurred from 1158 to 1252 UTC 3 Aug.

percentiles of the derived rainfall on 2 August versus the more continuous values on 3 August likely reflects different dynamical situations; the 3 August convective line was much more stationary than the early aircraft-sampled convective line on 2 August, and the clouds within the line had fewer/smaller gaps separating them. Despite the much shallower clouds on 3 August, comparable or even greater rainfall rates than 2 August were achieved in the clouds sampled by the aircraft. Higher-reflectivity regions occurring elsewhere on 2 August (not sampled by the aircraft) occurred in cloud clusters similar to those on 3 August.

\section{Method}

\section{a. Model description}

All numerical simulations were conducted using CM1 (Bryan and Fritsch 2002), a three-dimensional, nonhydrostatic, nonlinear, time-dependent numerical model designed for high-resolution, idealized studies of atmospheric phenomena. It was used here to solve the fully compressible form of the Navier-Stokes equations by employing time splitting for acoustic modes. For the uniform 150-m grid spacing, a time step of $1 \mathrm{~s}$ was used. Subgrid-scale turbulence was parameterized by a 1.5-order turbulence closure scheme. Open (radiative) boundary conditions were used for the horizontal boundaries of the domain, with a no-slip lower boundary condition and a Rayleigh damping layer within $1.75 \mathrm{~km}$ of the rigid upper boundary of the domain. The domain sizes were $36 \mathrm{~km} \times 63 \mathrm{~km} \times 10 \mathrm{~km}$ in the $x, y$, and $z$ directions for 2 August and $36 \mathrm{~km} \times$ $21 \mathrm{~km} \times 8 \mathrm{~km}$ for 3 August. (The much broader domain was needed on 2 August because of the greater wind speeds occurring on that day.) Simulations were run for $2 \mathrm{~h}$, but the strongest convection died out a little after $1 \mathrm{~h}$. The Coriolis force was neglected.

CM1 contains several options for bulk microphysics schemes; the National Severe Storms Laboratory (NSSL) double-moment microphysics scheme (Mansell et al. 2010) used here includes the warm rain scheme of Ziegler (1985), ice nucleation scheme of Meyers et al. (1992), and immersion freezing of raindrops by Bigg (1953). Rime splintering was calculated using the second formulation 
(based on droplet size) of Cotton et al. (1986). The NSSL microphysical scheme predicts mass and number concentration of cloud water, rain, cloud ice, aggregates (snow), graupel, and hail and also predicts the rime densities of graupel and hail for calculating their fall speeds more accurately. Default settings for the NSSL scheme were used except where noted.

\section{b. Simulation setup}

The environmental settings of the simulations were based upon the COPE balloonborne soundings released from the Davidstow radar site at 1500 UTC 2 or 3 August shown in Fig. 1. Prior to initialization of the model, superadiabatic layers near the surface of the soundings were removed and some lower levels were slightly cooled (for 2 August, surface temperature was decreased by $3^{\circ} \mathrm{C}$ and linearly interpolated to the original value at $935 \mathrm{hPa}$; for 3 August, temperature from the surface up to $830 \mathrm{hPa}$ was decreased by $1^{\circ} \mathrm{C}$ ) so that the heat flux forcing used to initiate the clouds (explained below) reproduced cloud-base heights near those observed.

To initiate the clouds in these environments, Gaussian surface-based heat fluxes were superimposed upon a line of weak low-level convergence to mimic the combined surface heating and the convergent forcing by sea breeze fronts propagating inward from the coastlines (Leon et al. 2016). Each Gaussian heat flux was prescribed as in Moser and Lasher-Trapp (2017) and was based upon the formulation of Carpenter et al. (1998): the peak heating occurred over a circular region at the surface, decreased radially, and decreased exponentially with height. Experimentation with the strength, location, and timing of these heat fluxes was performed so as to reproduce best the observed cloud-base heights, maximum cloud-top heights, and updraft speeds for both days. Weaker heat fluxes reduced the maximum cloud-top heights and updraft speeds attained, as did applying the heat fluxes for shorter time periods. The best location of the line of heat fluxes (and convergence) was experimentally determined to keep the storms in the domain for the maximum time possible, given the wind profiles of the soundings. The final values used for this study are given in Table 1. Four or five Gaussian fluxes were applied in a line across the domain to represent the lines of convective clouds observed on 2 or 3 August, respectively. The heat fluxes were staggered slightly in time in 100-s intervals to create (initially) discrete cells. The intensity of each heating function was increased linearly for $15 \mathrm{~min}$, was sustained at its maximum strength for $5 \mathrm{~min}$, and then was reduced to zero within $1 \mathrm{~min}$ (total forcing time of $21 \mathrm{~min}$ ). The maximum intensity of the heating functions needed for
TABLE 1. Cloud-initiation details for 2 and 3 August simulations.

\begin{tabular}{lrr}
\hline \multicolumn{1}{c}{ Parameter } & 2 Aug & 3 Aug \\
\hline No. of Gaussian surface heat fluxes & 4 & 5 \\
Max heating $\left(\mathrm{W} \mathrm{m}{ }^{-2}\right)$ & 3300 & 1800 \\
Gaussian width $\sigma(\mathrm{km} ; x, y$ direction) & \multicolumn{2}{c}{$2.5,3.5$} \\
Gaussian $e$-folding height $(\mathrm{km})$ & \multicolumn{2}{c}{0.35} \\
Time interval for staggered start of & 100 \\
$\quad$ Gaussian fluxes (s) & \multicolumn{2}{|c}{6} \\
Spacing between Gaussian heat flux & \multicolumn{2}{c}{ centers $(\mathrm{km})$} \\
\hline
\end{tabular}

3 August was $55 \%$ of that required for 2 August. Weak low-level convergence was also applied in both simulations homogeneously within $1500 \mathrm{~m}$ along the line and up to $350 \mathrm{~m}$ AGL for the full simulation time to mimic the effect of the sea breezes, using the CM1 initiation option that is based on Loftus et al. (2008) with the maximum convergence $D_{\max }=-3 \times 10^{-3} \mathrm{~s}^{-1}$.

To facilitate analysis of the lines of convection that were oriented with the wind along different diagonals within the southwestern England peninsula, the reference frame of the model domain and the input winds were rotated. On 2 August, shorter lines of clouds were nearly oriented north-south, and thus the lines of Gaussian fluxes were placed along a north-south line in the model domain. For the 3 August simulations, where the lines of convection were angled along the southwestnortheast direction (i.e., along the spine of the peninsula), the environmental wind directions were made westerly, and the lines of Gaussian heat fluxes were placed along a west-east line, making the rotated model domain and wind field simpler to analyze with standard north-south and east-west cross sections.

\section{c. Sensitivity tests}

Sensitivity tests were conducted to diagnose the dominant microphysical pathways to the surface rainfall in the simulations; specific changes are summarized in Table 2. A set of experiments designed to test the importance of the warm rain process in each case changed the $\mathrm{CCN}$ value in the model (representative of the number activated at a supersaturation of $1 \%$ ): halving that value from 600 to $300 \mathrm{~cm}^{-3}$ decreased the cloudbase droplet number concentration for the 2 August run (accelerating the warm rain process), and doubling it from 350 to $700 \mathrm{~cm}^{-3}$ increased the cloud-base droplet number concentration for the 3 August run (slowing the warm rain process). Additional simulations were performed with the melting of snow, graupel, and hail turned off to determine the importance of the warm rain process alone to surface rainfall in the control runs. Another set of sensitivity tests deactivating the rimesplintering process was used to evaluate its importance 
TABLE 2. Parameters changed for the main sensitivity tests discussed in the text.

\begin{tabular}{|c|c|c|c|c|c|c|}
\hline \multirow[b]{2}{*}{ Simulation } & \multicolumn{3}{|c|}{2 Aug parameters } & \multicolumn{3}{|c|}{3 Aug parameters } \\
\hline & $\mathrm{CCN}$ & Rime splintering & Melting & $\mathrm{CCN}$ & Rime splintering & Melting \\
\hline Control & 600 & On/off & On/off & 350 & On/off & On/off \\
\hline Half/double CCN & 300 & On/off & On/off & 700 & On/off & On/off \\
\hline Half vertical wind shear & 600 & On/off & On/off & 350 & On/off & On/off \\
\hline
\end{tabular}

to ice production in the clouds, as well as to the surface precipitation. Tests changing the primary ice nucleation formulation and turning off the Bigg (1953) parameterization of immersion freezing of supercooled raindrops were also conducted to address sensitivities to these model details. Simulations changing the input environmental wind profile on 2 August were used to investigate the effects of the strong vertical wind shear upon the various microphysical pathways to rainfall.

\section{Results}

\section{a. Comparison of control runs with observations}

In both the 2 August and 3 August simulations, the evolution of individual storms was very simple, consisting of a developing (cumulus) stage, a precipitating (mature) stage, and a dissipating stage, as in the classic "air mass thunderstorms" first depicted by Byers and Braham (1949). The Gaussian heat fluxes produced buoyant thermals that ascended to their levels of neutral buoyancy, and then decayed. As shown in Fig. 3, the main difference in the individual storms for the two simulations was that the deeper clouds and much stronger vertical wind shear on 2 August yielded clouds that leaned much more with height and had tops up to $3 \mathrm{~km}$ higher than those on 3 August.

The control runs generally agreed with the trends observed on each day, with some differences resulting from the idealized nature of the simulations. The clouds developed from the line of prescribed surface Gaussian heating functions, matured, and dissipated during the 2-h simulations. The cloud lifetimes were approximately $1 \mathrm{~h}$ in both simulations, with the cell lifetime in the 2 August simulation being less than that for the 3 August simulation. Determining accurate cloud lifetimes by tracking individual cells from the COPE ground-based radar proved difficult, especially on 2 August with the strong winds, but the simulations do not seem inconsistent with the radar observations in this regard. Plots of composited simulated radar reflectivity factor for the 2 and 3 August simulations (Fig. 4) exceeded $50 \mathrm{dBZ}$; the 3 August simulation also contained some values up to $60 \mathrm{~dB} Z$. The maximum cloud-top heights of $7.5 \mathrm{~km}$ for the 2 August case and $6 \mathrm{~km}$ for the
3 August case were attained at 40 and $45 \mathrm{~min}$, respectively. Not all cells reached these maximum heights, however, and this was consistent with the observations. The simulated cloud-base heights on 2 and 3 August were approximately $600 \mathrm{~m}$ (with temperatures of $\sim 12^{\circ}$ and $\sim 10^{\circ} \mathrm{C}$, respectively). Although the surface heat fluxes were of the same width and were operating for the same amount of time in both simulations, the 2 August clouds appeared wider in Fig. 4, as a result of the stronger vertical wind shear spreading hydrometeors downwind, and dissipated more quickly than those in the 3 August simulation.

The updraft speeds for the 2 and 3 August simulations were similar, having 99th-percentile values of $16 \mathrm{~m} \mathrm{~s}^{-1}$ at a height of $4 \mathrm{~km}$, but the 2 August clouds maintained maximum vertical velocities greater than $20 \mathrm{~m} \mathrm{~s}^{-1}$ over $15 \mathrm{~min}$ and to heights up to nearly $6 \mathrm{~km}$, whereas the 3 August case only contained these magnitudes for less than $5 \mathrm{~min}$. These trends are comparable to those sampled by the aircraft on 2 and 3 August but are about $5 \mathrm{~m} \mathrm{~s}^{-1}$ stronger than those observed on 3 August. This overestimate likely resulted from the stronger surface heating used in this simulation to force at least one cloud top to exceed 5-km height on 3 August; simulations with weaker forcing and shallower clouds had updraft speeds that were comparable to those observed. Because it was desirable to represent the coldest cloud tops observed to investigate ice formation, this simulation was used as the 3 August control case for the remainder of the study.

Figure 5 shows time series of the percentiles of 5-minaveraged surface precipitation rates and accumulations

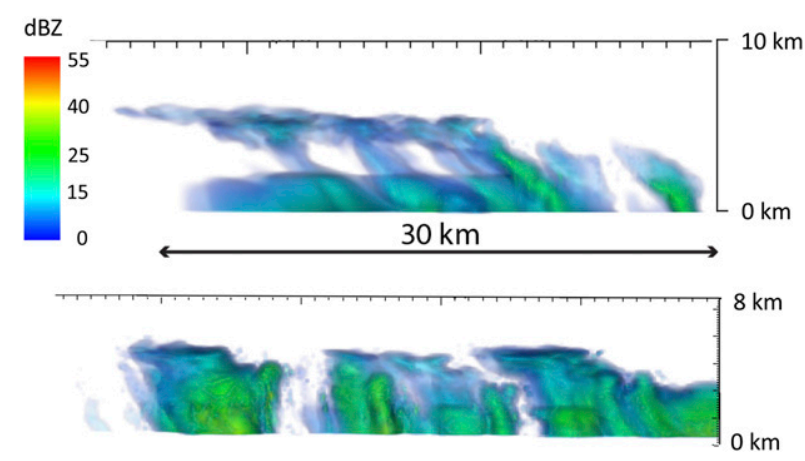

FIG. 3. Side views of 3D visualizations of simulated radar reflectivity for the (top) 2 Aug and (bottom) 3 Aug control simulations, with reflectivity color scale given in the legend $(\mathrm{dBZ})$. 

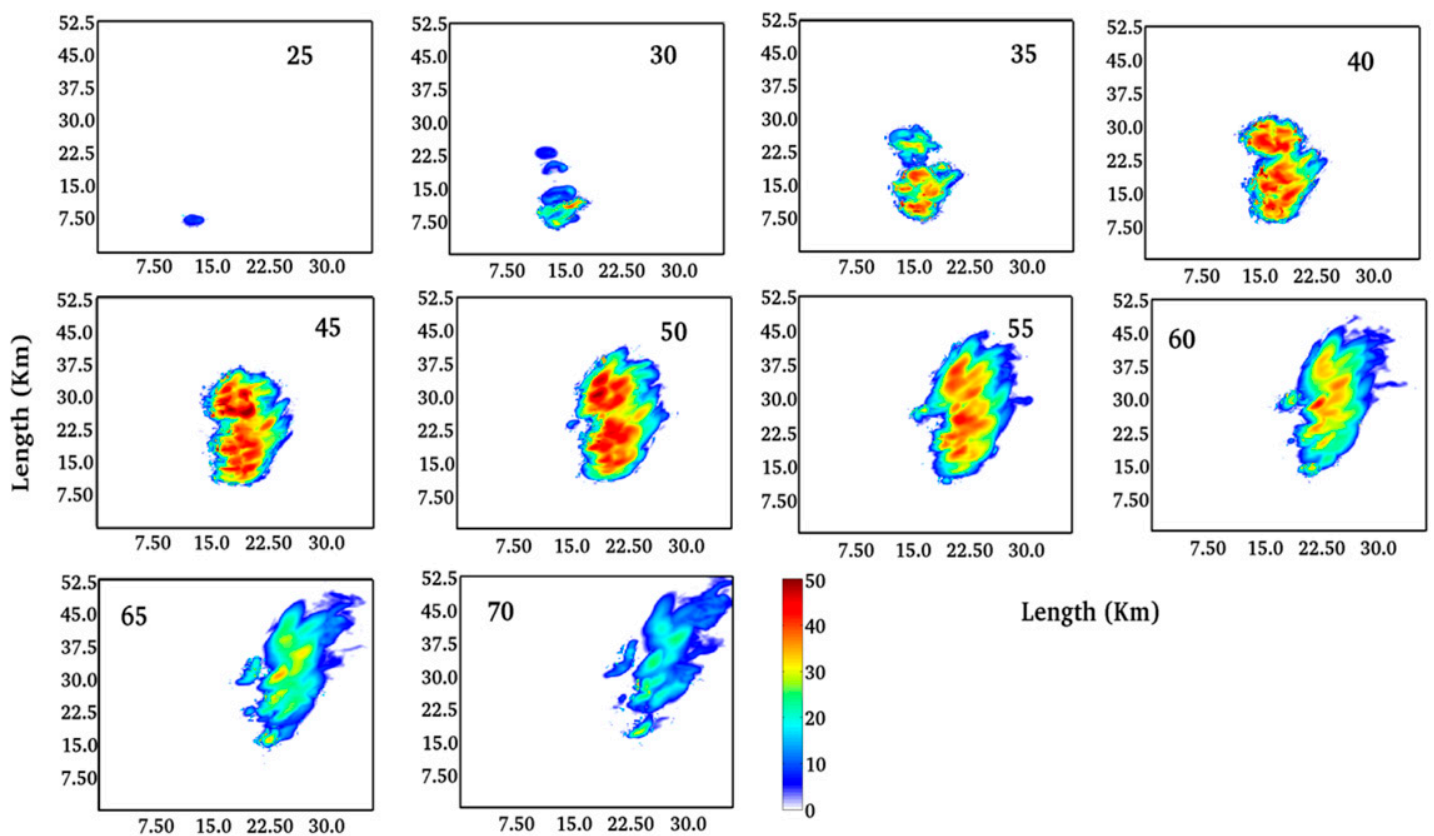

Length (Km)
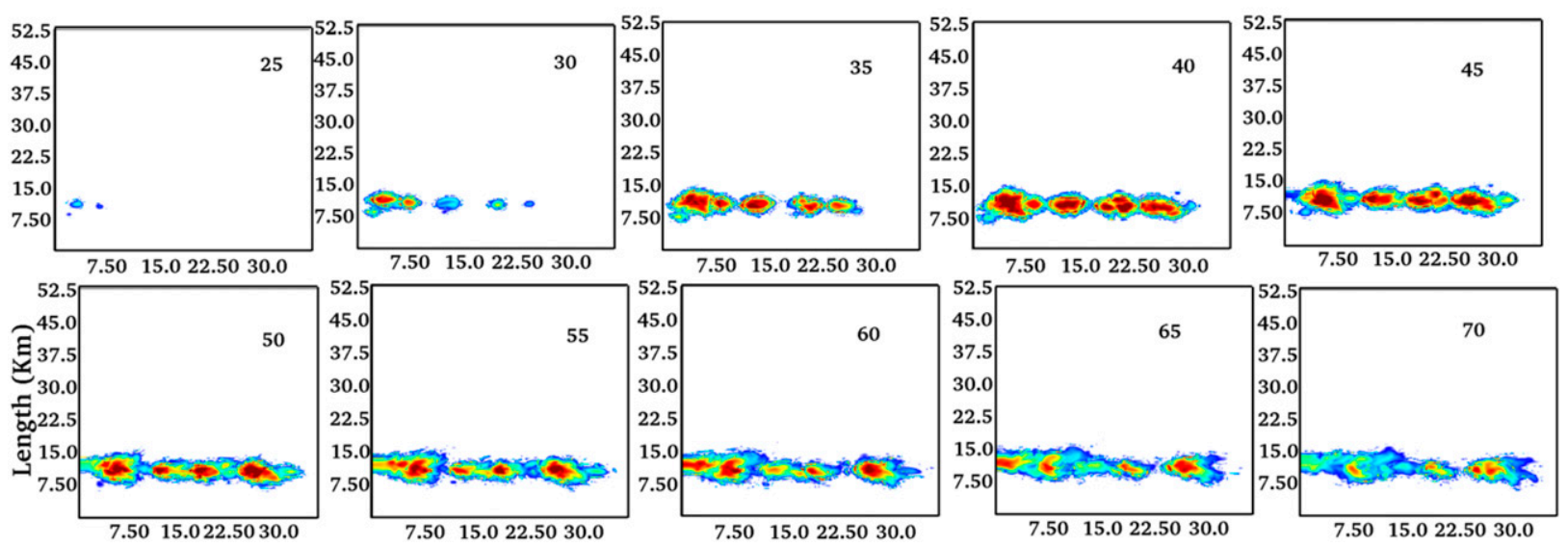

FIG. 4. Composite simulated radar reflectivity factor (color bar; $\mathrm{dBZ}$ ) over equivalent subsets of the model domain for control runs for (top) 2 Aug and (bottom) 3 Aug at 5-min intervals between 25 and $70 \mathrm{~min}$ from the start of the simulation (labeled at the top of each panel).

for the two simulations; they reproduce some of the trends in the observations but do not replicate the maxima estimated from the radar data (Fig. 2). The simulated rates for the 2 August case were much lower than those estimated from the radar data, especially at the higher percentiles. For the 3 August simulation, the rates were in excess of those derived from the NXPol radar measurements, except for the lowest percentiles. Yet the simulated rain rates did capture the trend in Fig. 2 where often the upper percentiles of the rain rates were less for 2 August than for 3 August (e.g., between 1400 and 1430 UTC). Despite the 2 August case having simulated cloud tops up to $2 \mathrm{~km}$ higher than those for
3 August, the 2 August case produced much less surface rainfall (1- vs 11-mm maximum), and much smaller rainfall rates $\left(14\right.$ vs $\left.155 \mathrm{~mm} \mathrm{~h}^{-1}\right)$ than the 3 August simulation. The dynamical and microphysical reasons for this trend are explored in the upcoming sections.

The in situ microphysical observations suggested that ice particles were much more common in the 3 August clouds than in the 2 August clouds, and the simulations also followed this trend (Fig. 6). Early in the simulations ( $25 \mathrm{~min}$ ) both showed comparable amounts of ice based on primary ice nucleation; the taller (and thus colder) cloud tops of the 2 August case at this time produced 

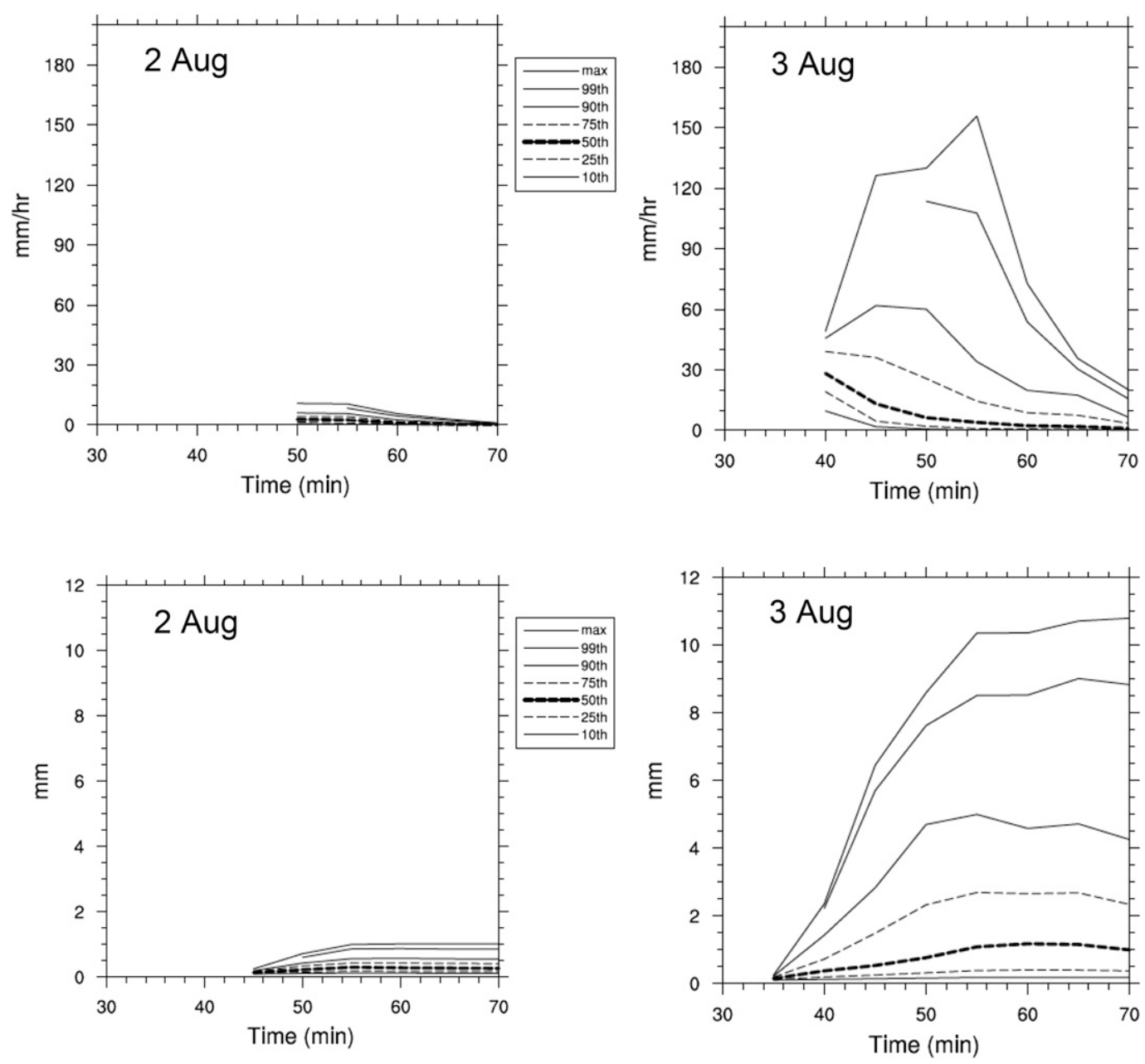

FIG. 5. Time series of percentiles (see legend) of (top) 5-min surface precipitation rate and (bottom) surface accumulation for the lowest grid points in the domain for the (left) 2 Aug and (right) 3 Aug control runs. Percentiles were only calculated when 10 or more samples occurred, which condition was met for the rate calculations 5 min after those for accumulation.

slightly more. In time, however, both cases developed much more ice, particularly within the rime-splintering zone (shaded), but the shallower 3 August clouds developed more ice (maximum of $190 \mathrm{~L}^{-1}$ ) than did the deeper 2 August clouds (maximum of $80 \mathrm{~L}^{-1}$ ). Particles exceeding $100 \mu \mathrm{m}$ in diameter measured in the rime-splintering zone by the aircraft on these two days numbered from 10 to $300 \mathrm{~L}^{-1}$ and were mostly ice on 3 August but still mostly liquid on 2 August (Jackson et al. 2018). The progression of microphysical processes leading to these differences in ice formation, and its effects upon surface rainfall, are explored in the following sections.

\section{b. The importance of the warm rain process}

There was observational evidence of a strong warm rain process on both days. The prevalence of columns of high $Z_{\mathrm{DR}}$ values often extending above the height of the melting level was presented in the radar study by Plummer et al. (2018). In both cases, the $Z_{\mathrm{DR}}$ values tended to be less than $4 \mathrm{~dB}$ but sometimes exceeded $4 \mathrm{~dB}$. The presence of large raindrops in the updrafts above the $0^{\circ} \mathrm{C}$ level was also found in the particle images collected from the aircraft (Jackson et al. 2018). The observed cloud-base temperatures were near $10^{\circ}$ and $12^{\circ} \mathrm{C}$ on 2 and 3 August respectively, but the 2 August clouds had over 2 times the maximum number of cloud droplets at their bases $\left(650 \mathrm{~cm}^{-3}\right)$ that 3 August had $\left(300 \mathrm{~cm}^{-3}\right)$. The higher droplet number concentrations on 2 August should slow the warm rain process (e.g., Rogers and Yau 1989; Pruppacher and Klett 2010) relative to 3 August, given the similar cloud-base thermodynamic conditions and updraft speeds. 

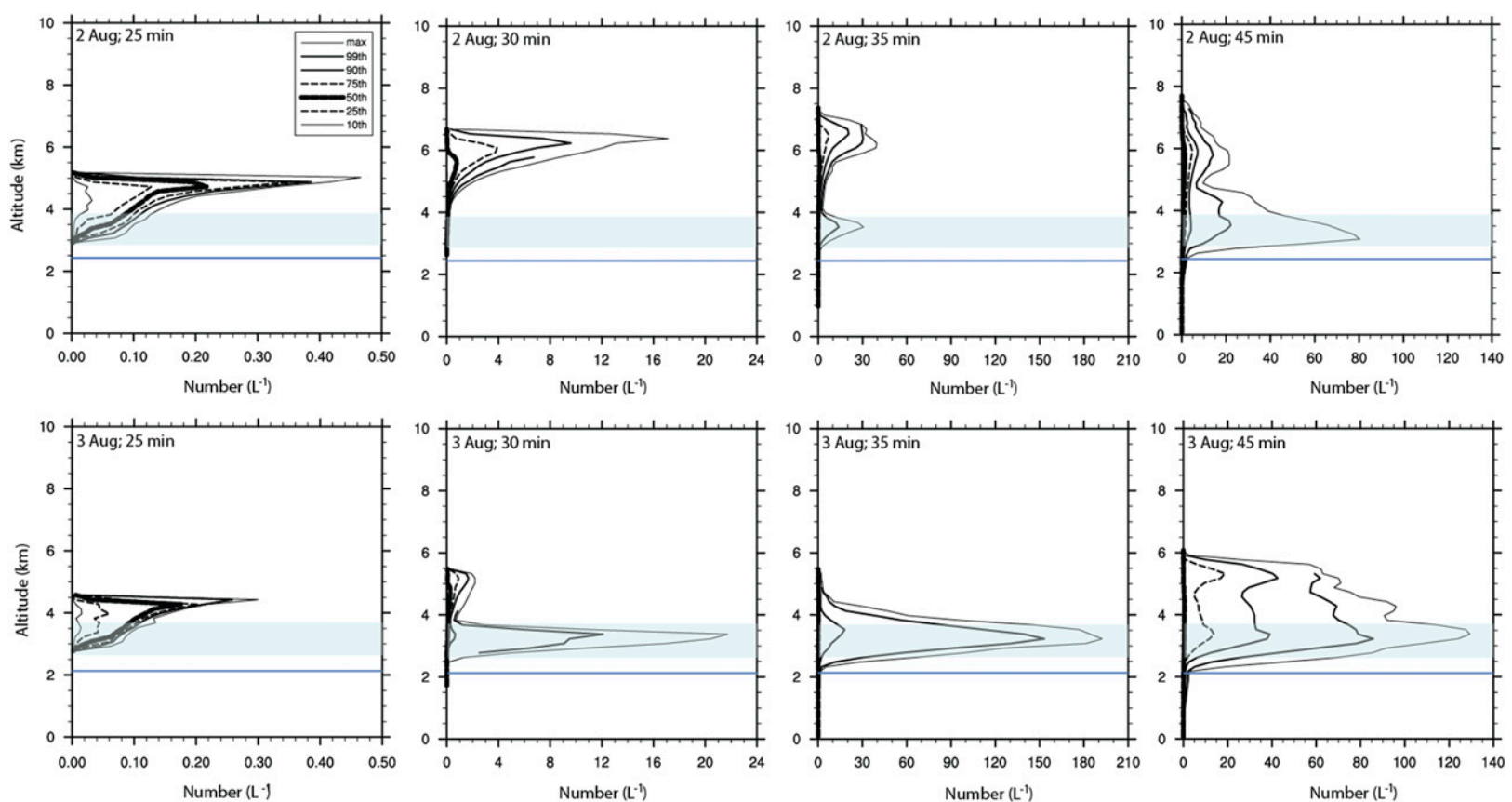

FIG. 6. Contoured-frequency-by-altitude diagrams (CFADs; Yuter and Houze 1995) of total ice number concentration at the time intervals shown for the (top) 2 Aug and (bottom) 3 Aug control runs. Percentiles are shown in legend. The horizontal blue line denotes the $0^{\circ} \mathrm{C}$ level; the shaded rectangle denotes the rime-splintering zone (from $-3^{\circ}$ to $-8^{\circ} \mathrm{C}$ ).

To understand the influence of the warm rain process in the simulations, the 2 August simulation was rerun with half the originally specified $\mathrm{CCN}$ (decreased from 600 to $300 \mathrm{~cm}^{-3}$ ), and the 3 August simulation was rerun with double its original CCN (increased from 350 to $700 \mathrm{~cm}^{-3}$ ). If the warm rain process was important to the simulated surface precipitation, then these experiments should increase or decrease the surface precipitation for the 2 or 3 August simulations, respectively. The results are shown in Fig. 7 (top panels). Although these shifts in precipitation did occur, in comparing the simulations in which the $\mathrm{CCN}$ amounts were similar (i.e., comparing the rainfall statistics for the 2 August doubled-CCN case and the 3 August control case, or the 2 August control case and the 3 August halved-CCN case) the surface rainfall was still much greater in the 3 August simulations, implying that the differences in the warm rain process alone on the two days does not explain the greater simulated rainfall in the shallower clouds on 3 August versus the deeper clouds on 2 August.

To estimate the contribution of the warm rain process to the overall surface rainfall, melting of frozen hydrometeors (snow, graupel, hail) was disabled, and the 2 and 3 August control simulations were rerun. Thus any rain falling to the ground within these simulations can only result from the warm rain process; falling snow, graupel, and/or hail would fall to the surface in their frozen form. ${ }^{4}$ Figure 7 (bottom panels) shows the percentage of the total precipitation mass at the lowest model level that was due to warm rain, snow, graupel, or hail alone, when melting was deactivated. Except for an initial miniscule amount of precipitation between 20 and $30 \mathrm{~min}$ in both simulations, the role of the warm rain process was very minor for the surface rainfall. The warm rain contribution was especially negligible $(0.026 \%)$ for the 2 August case and was generally less than $10 \%$ during the time of the heaviest precipitation for the 3 August case. (A higher contribution of warm rain was seen toward the end of both runs, as the convection started to die out.) For the simulations in which the 2 August $\mathrm{CCN}$ were halved or the 3 August $\mathrm{CCN}$ were doubled, the contribution of the warm rain process to surface rainfall (not shown) increased to $\sim 5 \%$ for 2 August and decreased to $3 \%$ for 3 August. In all of the simulations, the rainfall was almost exclusively derived from melted graupel.

\footnotetext{
${ }^{4}$ For these particular storm simulations, turning off the melting of frozen hydrometeors had only small effects on the overall storm dynamics and evolution. Although the decrease in latent cooling weakened the strongest downdrafts and thus decreased precipitation rates, for these simulations the overall precipitation mass at the lowest grid level was approximately $90 \%$ of the control run, except for the half/double CCN runs, which were $85 \%$ of the precipitation totals for the respective simulations that included melting.
} 

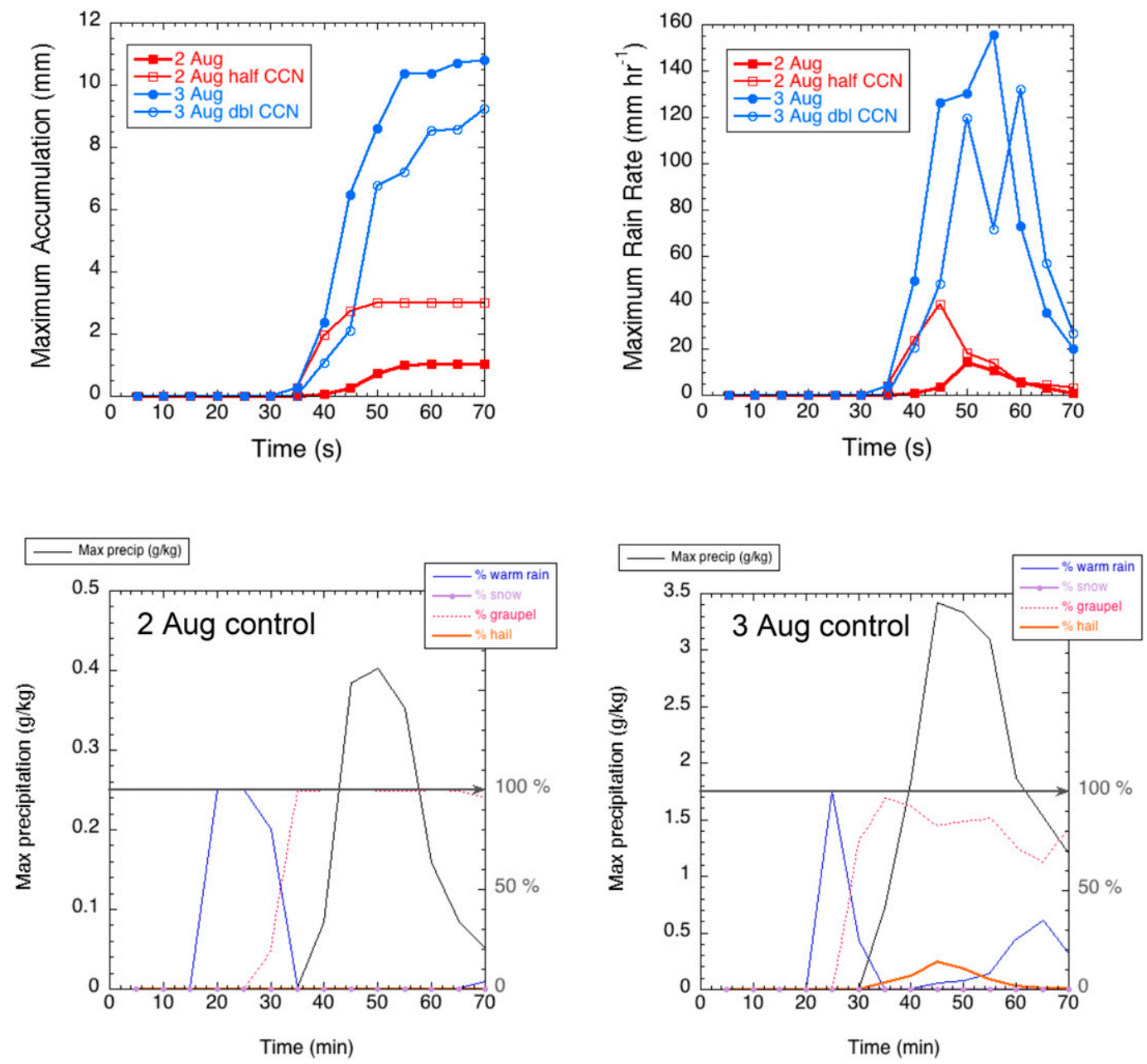

FIG. 7. (top) Time series of (left) maximum surface accumulated precipitation and (right) maximum rain rate for the control simulations and those for which $\mathrm{CCN}$ were changed, as described in the text. (bottom) Time series of maximum precipitation mass at the lowest grid level (black; scale on left) and percent of the total precipitation mass (scale on right) attributable to the hydrometeors shown in the legend, for the two control simulations with melting turned off.

From the results of these experiments, the warm rain process alone was not the dominant microphysical pathway to surface rainfall in the simulations; the majority of warm rain produced in the control simulations did not immediately fall out of the cloud, and thus must have been lofted within the updrafts where it contributed to ice processes (a different microphysical pathway). The working hypothesis of COPE was that a strong warm rain process could increase graupel production, if carried into colder parts of the cloud (instead of immediately falling out), by freezing and providing an earlier source of graupel that would create rime splinters, which themselves would rime and produce even more graupel. Such a pathway appears plausible because the simulated surface rainfall amounts did change when $\mathrm{CCN}$ were increased or decreased.
An inspection of the vertical distributions of warm rain mass and graupel mass above the $0^{\circ} \mathrm{C}$ level, along with some additional experimentation, explained their interdependence. The slower warm rain process on 2 August, as compared with 3 August, is clear from the warm rain mass shown in Fig. 8 (black curves), where smaller amounts of rain were produced overall and appeared higher (i.e., later, in an updraft) in the clouds. The first graupel (appearing after $25 \mathrm{~min}$ ) in both cases was produced by immersion freezing of the raindrops (Bigg 1953), as tested by independent experiments when that process was turned off in the model. Graupel mass was greater at lower altitudes $(2-5 \mathrm{~km})$ in the 3 August case than in the 2 August case; the graupel took lower trajectories in the shallower 3 August clouds and grew as they fell by the collection of cloud water and 

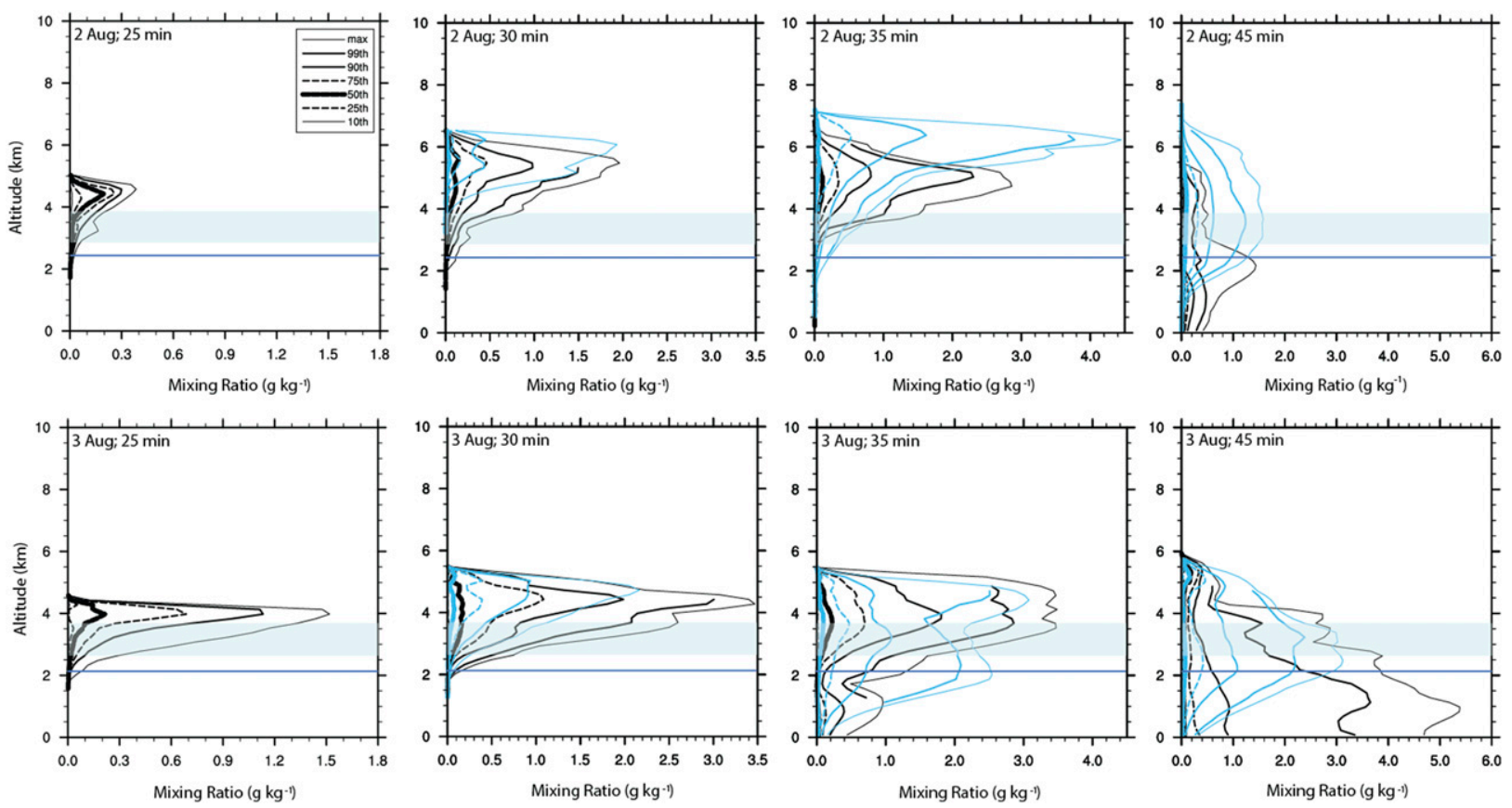

FIG. 8. CFADs of rain mixing ratio (black) and graupel mixing ratio (cyan) for the (top) 2 Aug and (bottom) 3 Aug control simulations at the times indicated. The height of the $0^{\circ} \mathrm{C}$ isotherm is shown as a dark-blue horizontal line, and the shaded box denotes the rimesplintering temperature zone.

supercooled raindrops. However, the deeper 2 August clouds had more graupel mass overall (and an order-ofmagnitude more graupel particles, up to $10 \mathrm{~L}^{-1}$ ), but at higher altitudes (maximum at $6 \mathrm{~km}$ ) because of the slower warm rain process and the stronger updrafts. This large amount of graupel for the 2 August case never translated to comparable amounts of surface rainfall, however, as compared with the 3 August case (panels at $45 \mathrm{~min}$ ), as a result of the much stronger vertical wind shear on 2 August as explored later in section 4d.

When increasing (decreasing) the $\mathrm{CCN}$ in the simulations, and thus slowing (accelerating) the warm rain process, the graupel mass contributing to surface rainfall decreased (increased), as diagnosed by turning off the melting in the simulations. Halving the $\mathrm{CCN}$ for the 2 August case not only increased the amount of warm rain falling to the surface but also helped to produce nearly 2 times the graupel mass contributing to rainfall at the lowest grid level (Fig. 9, top). The graupel mass was composed of fewer $(<50 \%)$ but larger particles when the warm rain process was faster. The results for the 3 August case were consistent with those for the 2 August case. Doubling the $\mathrm{CCN}$ for the 3 August case decreased the amount of warm rain falling to the surface and also decreased the graupel mass falling to the lowest grid level by nearly $25 \%$ (Fig. 9, bottom), now composed of more numerous but smaller graupel particles.

\section{c. The importance of rime splintering}

The expectations in COPE were that rime splintering would be an important source of ice to ultimately enhance the number of graupel and that it would be favored with a more active warm rain process. By comparing the control runs with those in which rime splintering was disabled (Fig. 10), the maximum numbers of ice particles in both control simulations was attributable to rime splintering. The ice number concentration maxima were approximately 80 and $190 \mathrm{~L}^{-1}$ for the 2 and 3 August control runs respectively, and occurred within or directly above the rime-splintering temperature zone. The 3 August maximum also occurred $10 \mathrm{~min}$ earlier than the 2 August maximum, which was consistent with the trend of the 3 August clouds producing raindrops earlier in the simulations. When rime splintering was disabled in the model, the shallower 3 August clouds had fewer ice particles than the deeper 2 August clouds, resulting from primary nucleation (mainly immersion freezing, as discussed earlier). Thus, at least in the model, rime splintering was responsible for the maxima in ice number concentrations in both cases but appeared to be much more active in the 3 August clouds than in the 2 August clouds, and thus it appeared to be consistent with the higher numbers of ice particles observed at those temperatures on 3 August.

Moreover, the warm rain process influenced the timing of secondary ice production by rime splintering in 

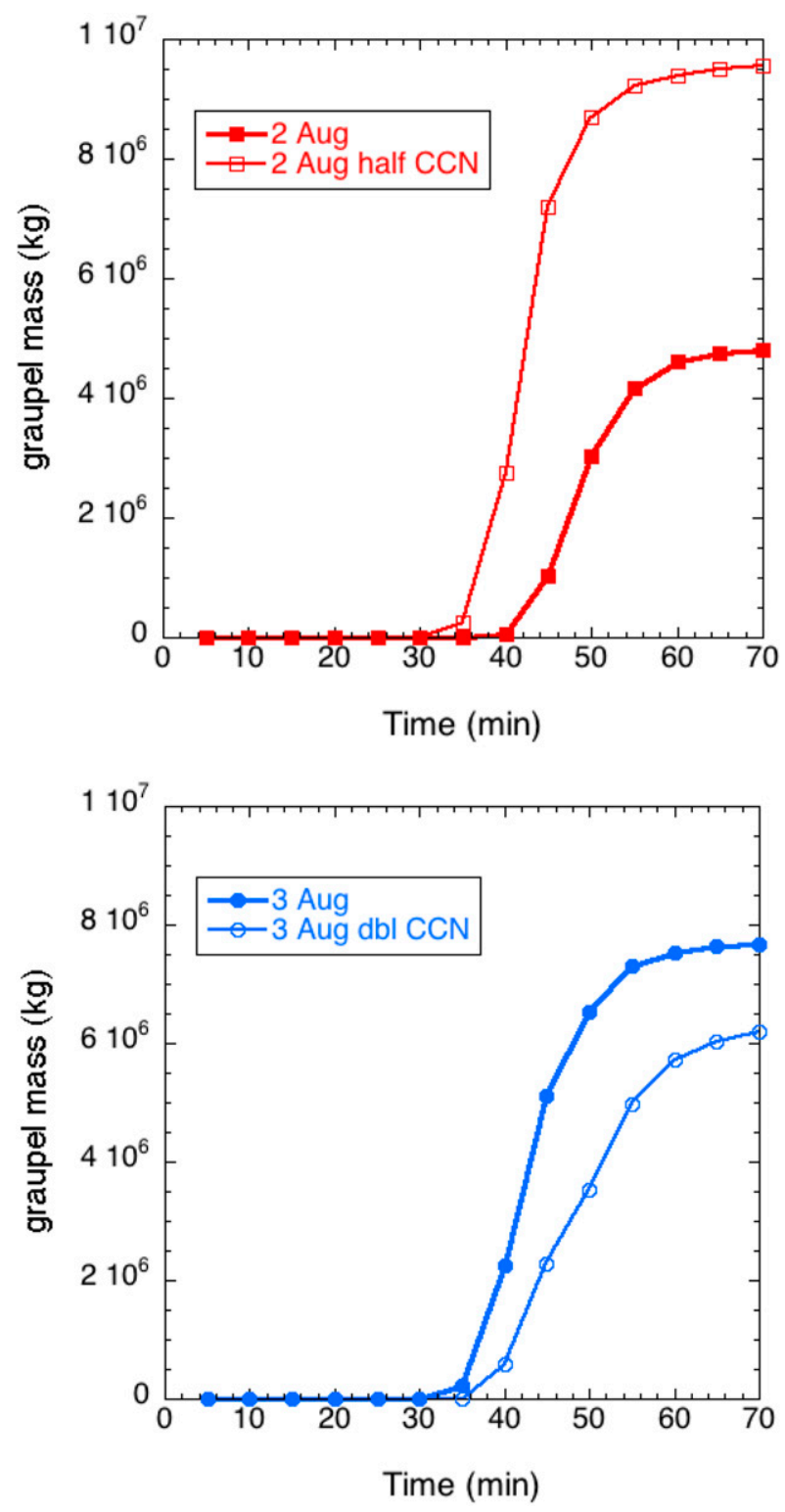

FIG. 9. Time series of total graupel mass at the lowest model level summed over the entire domain, diagnosed by turning off melting, for the (top) 2 Aug control and halved-CCN runs and (bottom) 3 Aug control and doubled-CCN runs. The magnitudes should not be compared across the two days because they are influenced by the different number of storms in the domain.

the simulations. When the number of 2 August $\mathrm{CCN}$ was halved, strengthening the warm rain process as discussed earlier, rime splintering commenced 10 min earlier (Fig. 11); a faster warm rain process led to larger graupel falling sooner through the rime-splintering zone. The doubled-CCN 3 August experiment was also consistent with this trend for the 50th-90th percentiles of total ice number concentration (Fig. 11, bottom row): slower warm rain formation at first delayed the productivity of the rime-splintering process, but by $45 \mathrm{~min}$ was nearly equivalent to the control case. (Interestingly, the 99th percentile and maxima exceeded the control run for the doubled-CCN case; different dynamics may be the reason, because the strongest updraft speeds within and directly above the rime-splintering zone were maintained a little longer in the doubled-CCN case.)

Although rime splintering was necessary in the model to reproduce ice crystal number concentrations similar to those observed, the extra ice it created appeared inconsequential to the simulated surface precipitation. Probability distribution functions of rain rate and surface accumulation for the 2 and 3 August simulations with rime splintering disabled were nearly identical (and thus not shown) to those of the control runs shown in Fig. 5, despite the several orders of magnitude difference in the number of ice particles. For the 2 August case, the percentiles of the graupel mixing ratios for the run with rime splintering disabled (not shown) were also identical to those of the control runs shown in Fig. 8, and those for the graupel number concentrations were nearly identical. However, for the 3 August case, the percentiles of the graupel mass mixing ratios (Fig. 12) had smaller values within and just outside the rimesplintering zone, after the time of onset of the rimesplintering process in the control run. The number of graupel particles (not shown) was reduced by nearly a factor of 4 (or more in the upper percentiles) in this region (75th percentiles decreased from 0.7 to $0.2 \mathrm{~L}^{-1}$, for example) when rime splintering was disabled. The graupel mass continued to be reduced throughout the simulation without rime splintering, but was compensated by more supercooled raindrop mass above the freezing level (Fig. 12, bottom row). The smaller amount of graupel in the upper percentiles translated into less rain near the ground in the upper percentiles, especially at 45 and $50 \mathrm{~min}$. The overall effect upon surface rainfall was minor, however, decreasing the maximum rain rate by only $\sim 5 \mathrm{~mm} \mathrm{~h}^{-1}$ (around 5\%), because warm rain (not converted to graupel by collisions with rime splinters) contributed more to the surface rainfall in this simulation (see the "warm rain" curve in Fig. 13; cf. the control case shown in Fig. 7). Thus, while the working hypothesis of COPE that a faster warm rain process could accelerate rime splintering and greatly increase the number of graupel does appear viable from the 3 August simulation, the hypothesized effect on surface rainfall was not realized, because of compensation by another microphysical pathway (warm rain).

\section{d. The effect of stronger wind shear on 2 August}

The previous sensitivity tests to investigate the microphysical pathways to surface rainfall suggested that despite colder cloud tops, the 2 August convection 

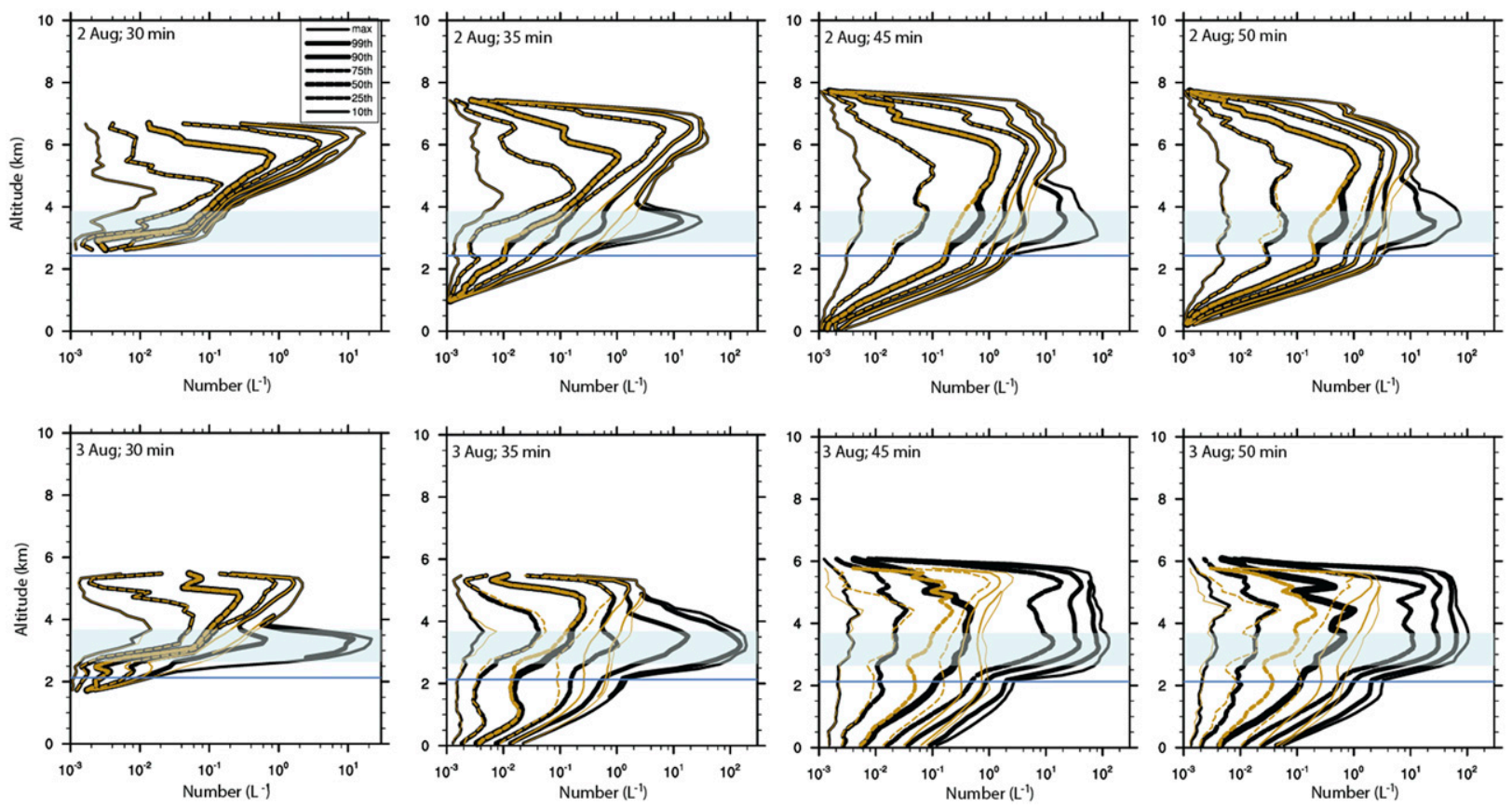

FIG. 10. Vertical profiles of percentiles of total ice number concentration for the control (black) and disabled rime splintering (gold) for the (top) 2 Aug and (bottom) 3 Aug simulations at the times indicated. The blue horizontal line denotes the height of the environmental $0^{\circ} \mathrm{C}$ level, and the shaded box denotes the rime-splintering zone.

contained fewer ice particles due to a less active rimesplintering process. They also suggested the 2 August convection had an abundance of graupel in the upper levels of the cloud, which in principle could have produced more surface rainfall than the 3 August simulation but did not. However, it is highly likely that dynamical differences in this case influenced the microphysical pathway to rainfall. As discussed in section 2, the deepest 2 August clouds
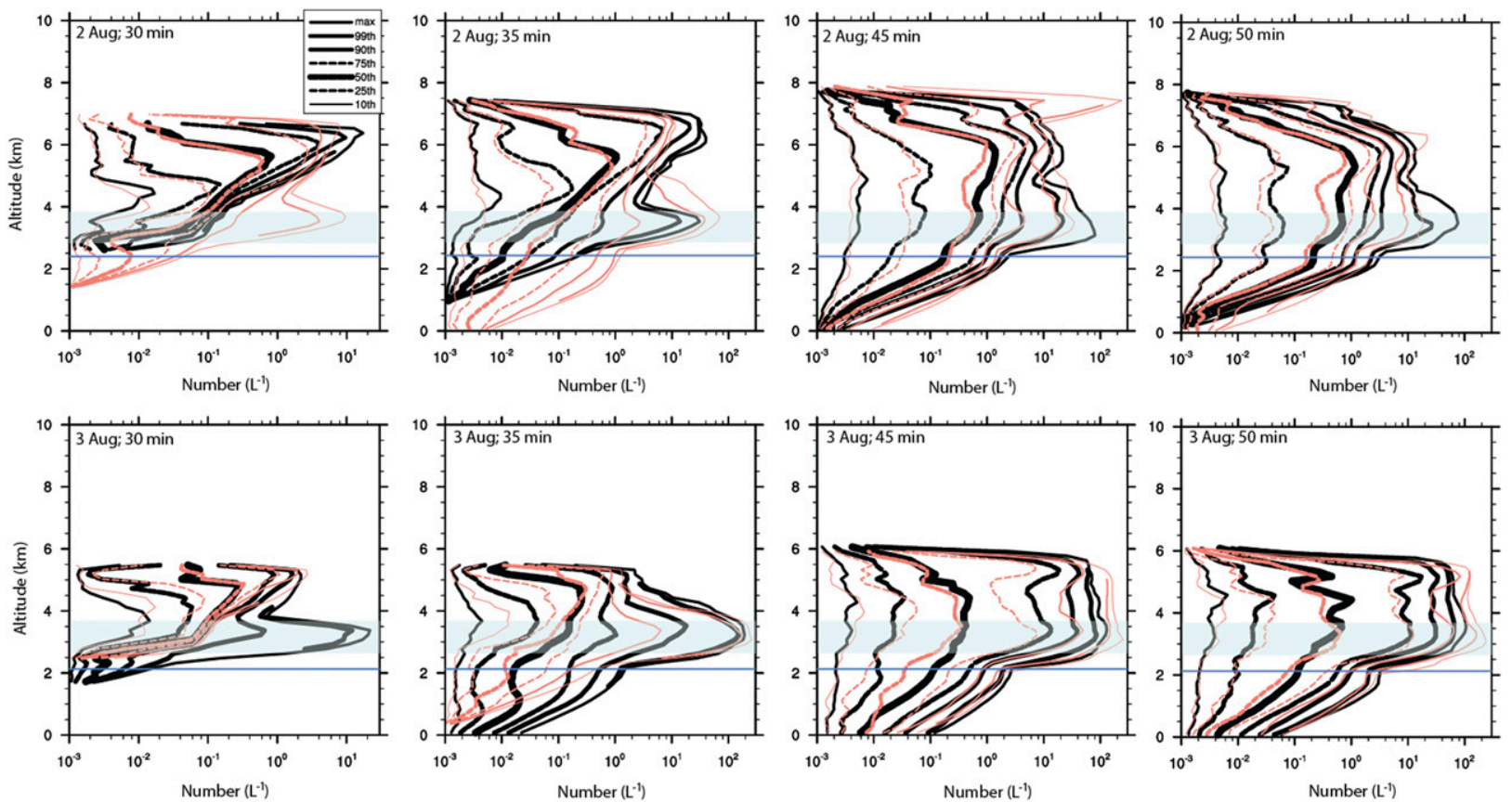

FIG. 11. As in Fig. 10, but comparing control (black curves) and halved-CCN (2 Aug) or doubled-CCN (3 Aug) (orange curves) simulations. 

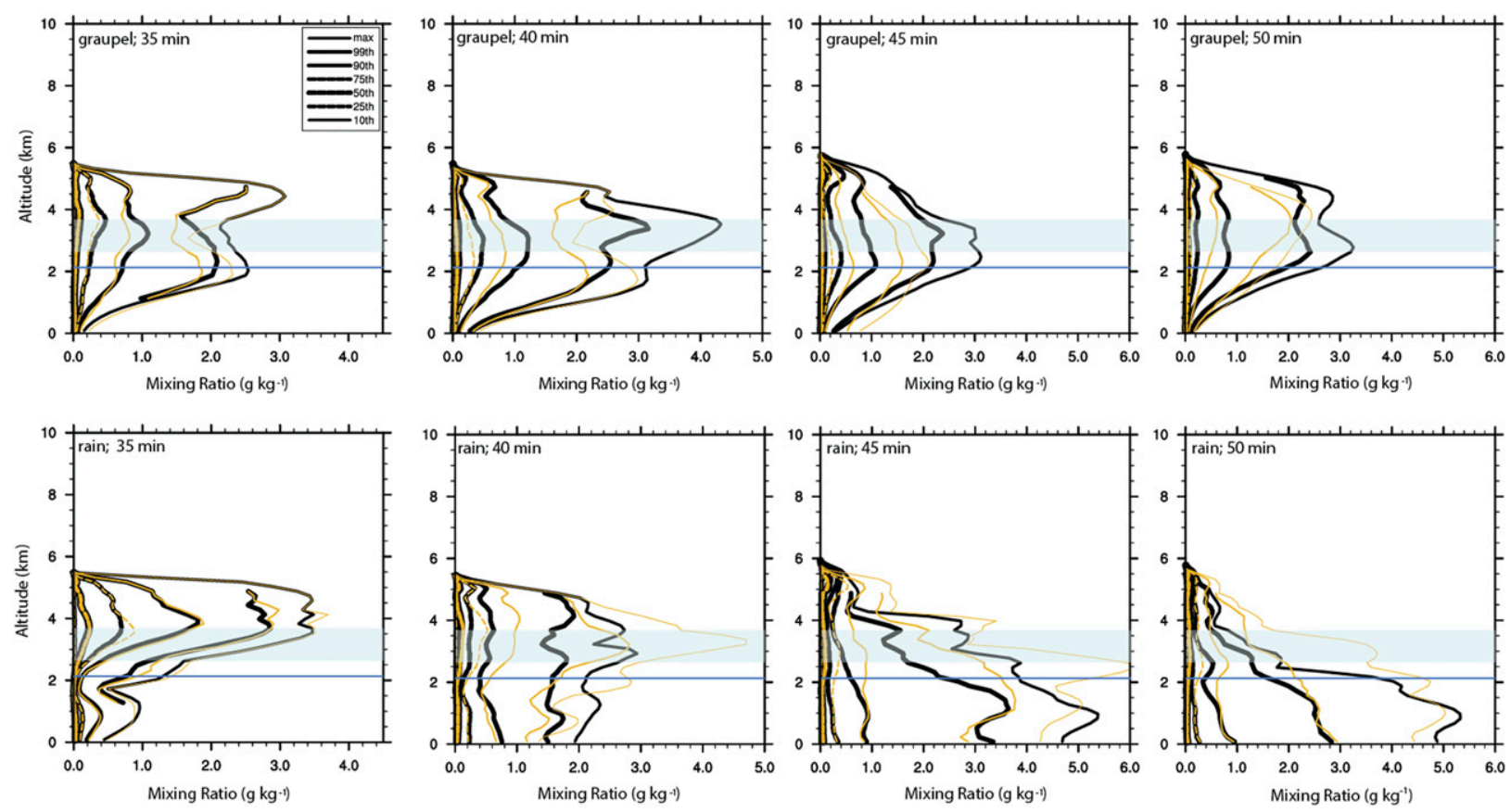

FIG. 12. Series of CFADs of (top) graupel mass and (bottom) rain mass at times labeled for the 3 Aug control run (black curves) and norime-splintering run (gold curves). The height of the $0^{\circ} \mathrm{C}$ isotherm is shown as a blue horizontal line, and the rime-splintering zone is shaded.

had more vertical wind shear over the cloud depths by nearly an order of magnitude than did the shallower 3 August clouds. Vertical cross sections through the simulated 2 August clouds (Fig. 14) indicated that the clouds leaned with height, such that the graupel maxima near the top of the clouds would not fall into cloud below. Thus, when graupel fell through the temperature range for rime splintering, they would have encountered little or no cloud water (Fig. 14, bottom panel) to grow by riming or to activate the rime-splintering process.

The effect of the strong vertical wind shear on 2 August, and its possible effect on rime splintering and surface rainfall, were explored with an additional set of simulations. Here, the wind profile of the sounding used to initialize the model was changed: the 2 August wind speeds were decreased to replicate those on 3 August, as shown in Fig. 2 (purple profile), so that the vertical wind shear from cloud base up to comparable heights was identical. For the same cloud forcing, decreasing the vertical wind shear on 2 August allowed the updraft to be stronger $\left(\sim 3 \mathrm{~m} \mathrm{~s}^{-1}\right)$ and the cloud top to ascend higher $(\sim 500 \mathrm{~m})$. The clouds leaned less with height because of the decreased vertical wind shear, and they lasted approximately 20 min longer. Vertical cross sections showed that the graupel in the upper regions of the cloud was no longer downwind of the cloud water below (Fig. 14, second column).

Greater ice number concentrations were produced in the reduced-shear run (Fig. 15). Most notably, the number of ice particles near the cloud top was much greater, as not only more primary ice was nucleated at the colder cloud tops, but also more rime splinters were carried aloft to the cloud top, and the ice near cloud top was no longer pulled away from the cloud by strong winds as in the control case. More ice was created in the rime-splintering zone as graupel now

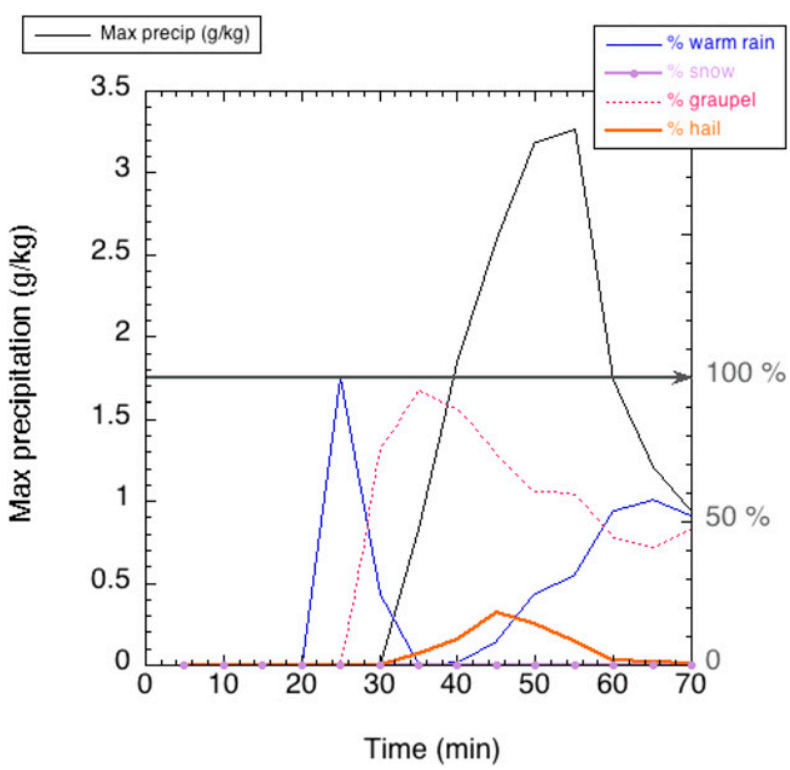

FIG. 13. As in the bottom panels of Fig. 7, but for the 3 Aug simulation with rime splintering disabled. 

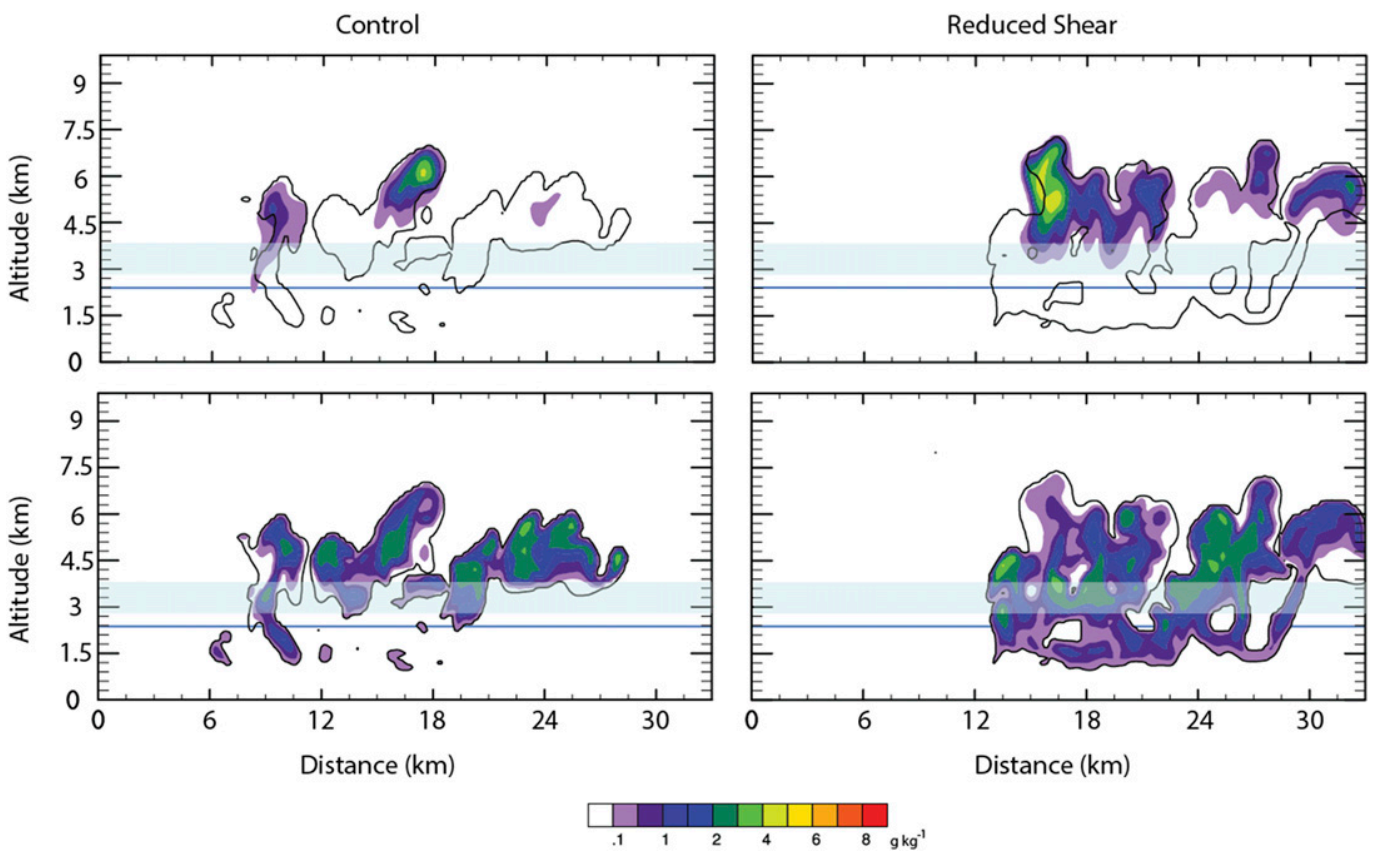

FIG. 14. North-south vertical cross sections of (top) graupel mass and (bottom) cloud water mass, for the 2 Aug (left) control run and (right) reduced-shear run, at $35 \mathrm{~min}$ into the simulations. The blue horizontal line denotes the height of the environmental $0^{\circ} \mathrm{C}$ level, and the shaded box denotes the rime-splintering zone.

fell through it while collecting cloud water: the maximum number of ice particles attained in the simulation was 2 times as large as in the control case (up to $160 \mathrm{~L}^{-1}$ ) and was nearly comparable to the 3 August case (maximum of $180 \mathrm{~L}^{-1}$ ).

Both rain and graupel mass increased significantly throughout the cloud depth in the reduced-shear simulation (Fig. 16), collecting more cloud water than in the control case. Two times as much graupel mass was produced in the reduced shear case, and it extended throughout the cloud depth. As it fell beneath the melting level, it contributed to substantially more rain mass reaching the ground. The maximum rain accumulation and rain rates (Fig. 17) increased accordingly (from 1 to $4 \mathrm{~mm}$ and from 8 up to $30 \mathrm{~mm} \mathrm{~h}^{-1}$, respectively). It was not simply the case that an equal amount of rain was spread over a smaller area when the winds were reduced, because the domain-integrated surface rainfall was 3 times that of the control run.

\section{Conclusions and discussion}

Idealized three-dimensional simulations of two consecutive days of convection observed during the COPE field campaign in southwestern England were analyzed to understand the possible microphysical pathways leading to surface rainfall. The primary hypothesis was that a stronger warm rain process would accelerate graupel production and also thereby the creation of secondary ice by rime splintering, which would then
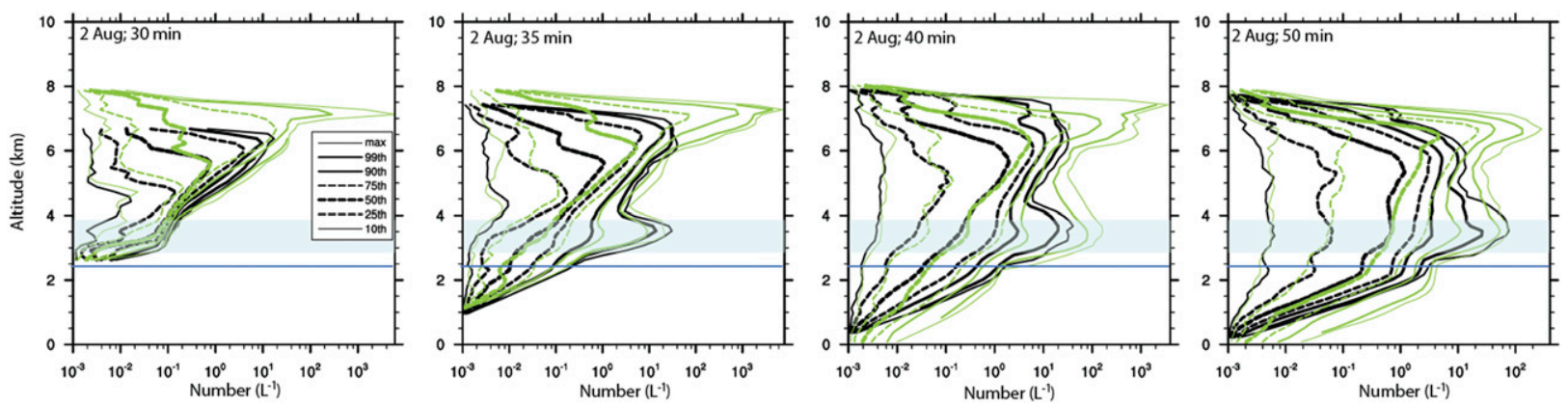

FIG. 15. CFADs of total ice number concentration for the 2 Aug control simulation (black) and the 2 Aug simulation with halved vertical wind shear (green). The height of the $0^{\circ} \mathrm{C}$ isotherm is shown by a blue horizontal line, and the rime-splintering zone is shaded. 

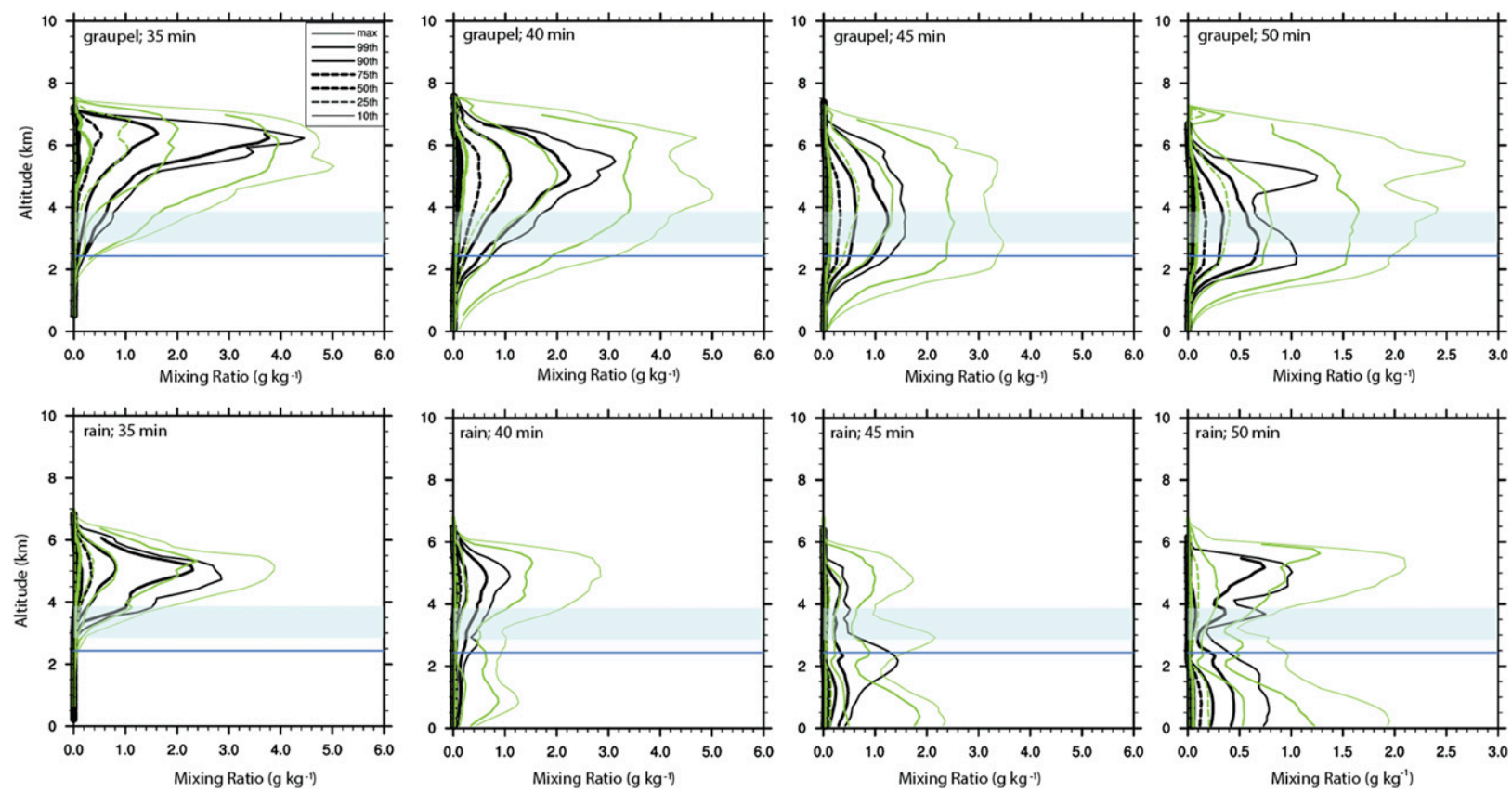

FIG. 16. As in Fig. 15, but for (top) graupel mass and (bottom) rain mass at the time intervals shown for the 2 Aug control run (black) and the 2 Aug run with reduced vertical wind shear (green).

grow by riming cloud water to produce more graupel and, ultimately, heavy surface rainfall. This study produced the following findings:

- The warm rain process was active in the convection on both days but was quicker in the 3 August case, as a result of lower number concentrations of cloud droplets, and was stronger because it lacked the vertical wind shear of the 2 August case that would limit the collection of cloud water by falling raindrops. The warm rain process was not the dominant microphysical pathway to surface rainfall, contributing less than $10 \%$ to the major rainfall. It was, however, an important contribution in forming earlier, larger graupel particles.

- Rime splintering was active in the simulated convection on both days but less so in the deeper, sheared clouds on 2 August. Total ice number concentrations exceeded $100 \mathrm{~L}^{-1}$ in the rime-splintering zone for the 3 August case, whereas the 2 August case had an orderof-magnitude fewer ice numbers. The rime-splintering process in the 2 August simulation was hindered by the stronger vertical wind shear, which advected most of the graupel aloft downstream, falling mainly outside of cloud, where it could not grow by riming or produce rime splinters. When the 2 August case was simulated with shear magnitudes that were comparable to those on 3 August, comparable amounts of ice were created in the rime-splintering zone.
- In the simulations, the primary microphysical pathway to surface precipitation on both days was warm rain lofted above the $0^{\circ} \mathrm{C}$ isotherm by strong updrafts; supercooled raindrops froze by immersion freezing and/or collision with primary nucleated ice (or later rime splinters) to form graupel, which grew by riming and ultimately melted as it fell beneath the $0^{\circ} \mathrm{C}$ isotherm to produce surface rainfall.

- The rime-splintering process was the dominant contributor to the high ice number concentrations (near or exceeding $100 \mathrm{~L}^{-1}$ ) in the simulated clouds, but sensitivity tests suggested that it was not essential to producing the surface rainfall. When the rime-splintering process was disabled, less supercooled rain was converted to graupel but then contributed more to the surface rainfall $(>50 \%)$, ultimately yielding nearly similar surface accumulations. Therefore, a strong warm rain process, which can produce both graupel and thus rime splinters more quickly, competed with those rime splinters for the available cloud water for accretion. Thus, the hypothesis that this microphysical pathway ultimately produces more rainfall was not realized in these simulations.

Although the convection simulated here was based upon the observed 2 and 3 August COPE cases, the highly idealized setting, the initiation and framework of the simulations, the limited model resolution, and uncertainties with respect to the representations of the 

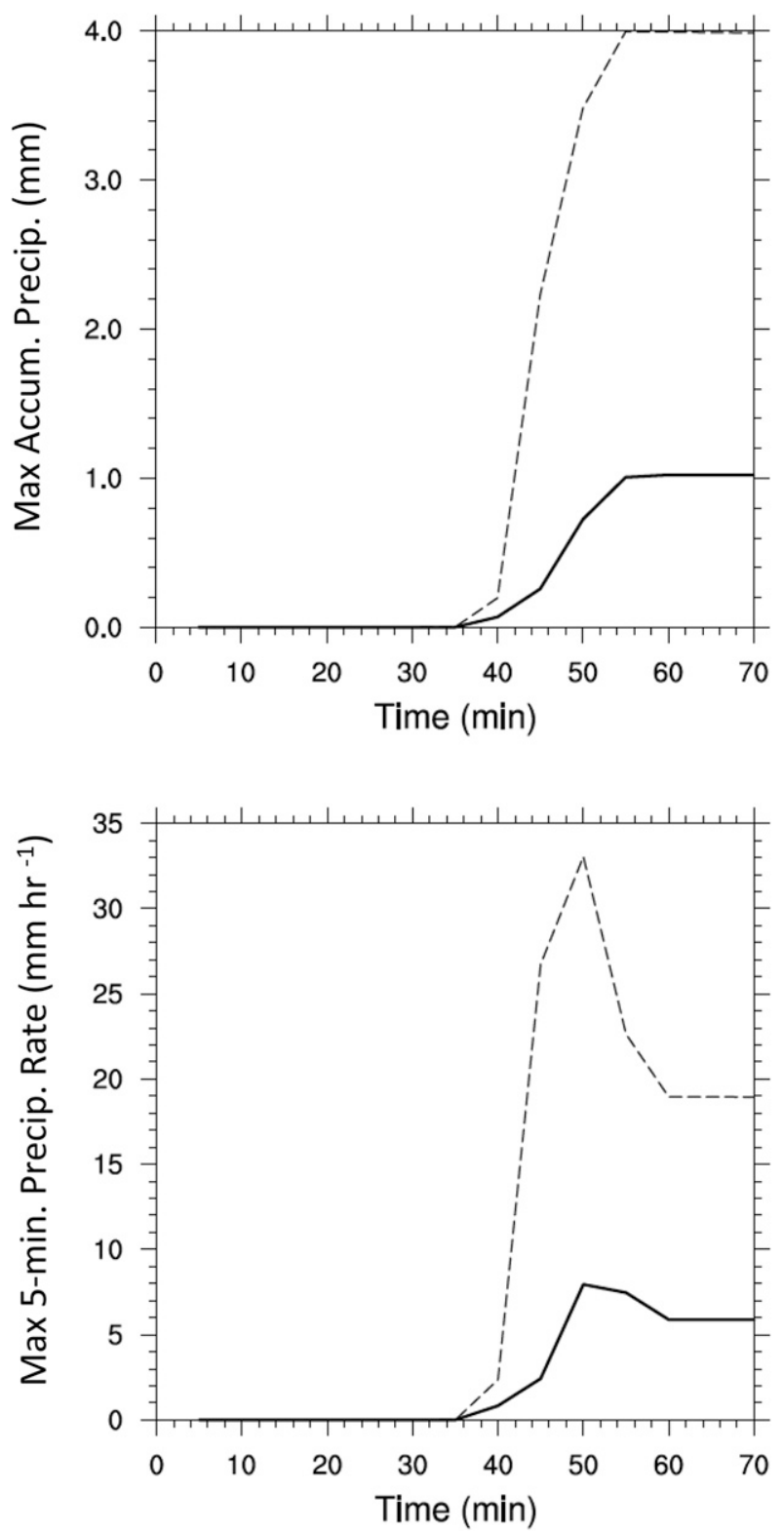

FIG. 17. Time series of (top) maximum accumulated precipitation $(\mathrm{mm})$ at the surface at any grid point and (bottom) maximum 5-min precipitation rate $\left(\mathrm{mm} \mathrm{h}^{-1}\right)$ at the surface for the 2 Aug control run (solid curve) and run with halved vertical wind shear (dashed curve).

microphysics themselves make it impossible to conclude that the microphysical pathways that occurred in the simulations were identical to those that occurred in reality on these days. In particular, the clouds simulated for 3 August were more representative of the deepest clouds of that day, but others were not as deep, and indeed simulations based upon those shallower cases have implicated the warm rain process in being more important for surface rainfall (Moser and Lasher-Trapp 2017, 2018). Weaker updrafts would allow raindrops to fall out of the cloud more quickly rather than being lofted to higher and colder levels in the clouds. In addition, while the simulations used here were performed with $150-\mathrm{m}$ grid spacing, smaller grid spacings would capture even more detail and inhomogeneity and typically greater localized maxima in the microphysical variables than were reported here. Furthermore, the actual convection on both days was of much longer duration than the run time of the simulations used here, and thus neither multiple life cycles nor interaction between different stages of clouds were represented in the simulations. For example, while the 2 August case simulated here produced very minor rainfall, it is highly possible that a "seeder-feeder" mechanism occurred between ice-laden cloud tops blown downwind from older convection and water-dominated shallower clouds below, producing temporary bursts of enhanced rainfall, like those shown in the radar-derived precipitation rates shown in Fig. 2. Such discrepancies illustrate that representing the upper percentiles of convective rainfall will always remain challenging, because they can result from specific dynamical aspects of individual clouds that are poorly captured in numerical models.

While the COPE hypothesis that a quicker warm rain process can produce supercooled raindrops earlier, and thus graupel earlier, was supported by these simulations, these effects were not realized as additional rainfall. The competition between warm rain and graupel for growth by collecting cloud water resulted in nearly the same amount of surface rainfall. More work is needed to investigate the relative importance of warm rain and ice processes in a variety of storm environments.

The cases studied here produced some intriguing results that also warrant further investigation into the accuracy of current microphysical parameterizations used in numerical models. While the understanding and quantification of secondary ice nucleation processes like rime splintering are of interest (Field et al. 2017) and could have important implications for cloud radiative properties for example, the simulations here suggested that bursts of large numbers of ice crystals might not be as useful to producing additional surface rainfall as has been hypothesized, at least in cases with a strong warm rain process. Sensitivity tests conducted with the immersion freezing of raindrops disabled (Bigg 1953) also ultimately had little effect on the surface rainfall, nor did tests (not shown) using the Fletcher (1962) parameterization for primary ice-nucleating particles instead of the Meyers et al. (1992) parameterization. These tests also suggested that the microphysical pathways to surface rainfall in the model compensate for more or fewer icenucleating particles, perhaps again through the warm rain process. Future work must determine whether this 
compensation is accurate or is possibly a limitation of the microphysical parameterization scheme used here; studies using bin-resolving microphysical schemes may be useful in this regard.

Acknowledgments. The CM1 model is maintained and distributed by Dr. George Bryan of the National Center for Atmospheric Research, funded by the National Science Foundation, and Dr. Ted Mansell of the National Severe Storms Laboratory maintains and distributes the NSSL microphysical scheme that was employed here. Three anonymous reviewers helped to clarify multiple aspects of the manuscript. All computations were run on the University of Illinois Department of Atmospheric Science's computing cluster. The Convective Precipitation Experiment was funded by the UK Natural Environment Research Council (NERC), the Met Office, and the National Science Foundation. Support for this study was from NSF awards AGS-1230292, AGS-1230203, and AGS-1441831 and NERC award NE/J023507/1.

\section{REFERENCES}

Bigg, E. K., 1953: The formation of atmospheric ice crystals by the freezing of droplets. Quart. J. Roy. Meteor. Soc., 79, 510-519, https://doi.org/10.1002/qj.49707934207.

Braham, R. R., Jr., 1964: What is the role of ice in summer rainshowers? J. Atmos. Sci., 21, 640-645, https://doi.org/10.1175/ 1520-0469(1964)021<0640:WITROI >2.0.CO;2.

Bryan, G. H., and J. M. Fritsch, 2002: A benchmark simulation for moist nonhydrostatic numerical models. Mon. Wea. Rev., 130, 2917-2928, https://doi.org/10.1175/1520-0493(2002)130<2917: ABSFMN $>2.0 . C O ; 2$.

Byers, H. R., and R. R. Braham Jr., 1949: The Thunderstorm. U.S. Government Printing Office, 287 pp.

Carpenter, R. L., K. K. Droegemeier, and A. M. Blyth, 1998: Entrainment and detrainment in numerically simulated cumulus congestus clouds. Part II: Cloud budgets. J. Atmos. Sci., 55, 3433-3439, https://doi.org/10.1175/1520-0469(1998)055<3433: EADINS $>2.0 . \mathrm{CO} ; 2$.

Chisnell, R. F., and J. Latham, 1976: Ice particle multiplication in cumulus clouds. Quart. J. Roy. Meteor. Soc., 102, 133-156, https://doi.org/10.1002/qj.49710243111.

Cotton, W. R., G. J. Tripoli, R. M. Rauber, and E. A. Mulvihill, 1986: Numerical simulation of the effects of varying ice crystal nucleation rates and aggregation processes on orographic snowfall. J. Climate Appl. Meteor., 25, 1658-1680, https://doi.org/ 10.1175/1520-0450(1986)025<1658:NSOTEO > 2.0.CO;2.

Field, P. R., and Coauthors, 2017: Secondary ice production: Current state of the science and recommendations for the future. Ice Formation and Evolution in Clouds and Precipitation: Measurement and Modeling Challenges, Meteor. Monogr., No. 58, Amer. Meteor. Soc., https://doi.org/10.1175/AMSMONOGRAPHS-D-16-0014.1.

Fletcher, N. H., 1962: The Physics of Rainclouds. Cambridge University Press, 386 pp.

Golding, B., P. Clark, and B. May, 2005: The Boscastle flood: Meteorological analysis of the conditions leading to flooding on 16 August 2004. Weather, 60, 230-235, https://doi.org/ 10.1256/wea.71.05.
Hallett, J., R. I. Sax, D. Lamb, and A. S. R. Murty, 1978: Aircraft measurements of ice in Florida cumuli. Quart. J. Roy. Meteor. Soc., 104, 631-651, https://doi.org/10.1002/qj.49710444108.

Huang, Y., and Coauthors, 2008: The development of ice in a cumulus cloud over southwest England. New J. Phys., 10, 105021, https://doi.org/10.1088/1367-2630/10/10/105021.

Jackson, R., J. R. French, D. C. Leon, D. M. Plummer, S. LasherTrapp, A. M. Blyth, and A. Korolev, 2018: Observations of the microphysical evolution of convective clouds in the southwest United Kingdom. Atmos. Chem. Phys., https://doi.org/10.5194/ acp-2018-437, in press.

Koenig, L. R., 1963: The glaciating behavior of small cumulonimbus clouds. J. Atmos. Sci., 20, 29-47, https://doi.org/10.1175/ 1520-0469(1963)020<0029:TGBOSC > 2.0.CO;2.

Leon, D. C., and Coauthors, 2016: The Convective Precipitation Experiment (COPE): Investigating the origins of heavy precipitation in the southwestern United Kingdom. Bull. Amer. Meteor. Soc., 97, 1003-1020, https://doi.org/10.1175/BAMS-D14-00157.1.

Loftus, A. M., D. B. Weber, and C. A. Doswell, 2008: Parameterized mesoscale forcing mechanisms for initiating numerically simulated isolated multicellular convection. Mon. Wea. Rev., 136, 2408-2421, https://doi.org/10.1175/2007MWR2133.1.

Mansell, E. R., C. L. Ziegler, and E. C. Bruning, 2010: Simulated electrification of a small thunderstorm with two-moment bulk microphysics. J. Atmos. Sci., 67, 171-194, https://doi.org/ 10.1175/2009JAS2965.1.

Meyers, M. P., P. J. DeMott, and W. R. Cotton, 1992: New primary ice-nucleation parameterizations in an explicit cloud model. J. Appl. Meteor., 31, 708-721, https://doi.org/10.1175/15200450(1992)031<0708:NPINPI>2.0.CO;2.

Moser, D. H., and S. Lasher-Trapp, 2017: The influence of successive thermals on entrainment and dilution in a simulated cumulus congestus. J. Atmos. Sci., 74, 375-392, https://doi.org/ 10.1175/JAS-D-16-0144.1.

$\longrightarrow$, and — 2018: Cloud spacing effects upon entrainment and rainfall along a convective line. J. Appl. Meteor. Climatol., 57, 1865-1882, https://doi.org/10.1175/JAMC-D-17-0363.1.

Ovtchinnikov, M., and Y. L. Kogan, 2000: An investigation of ice production mechanisms in small cumuliform clouds using a $3 \mathrm{D}$ model with explicit microphysics. Part I: Model description. J. Atmos. Sci., 57, 2989-3003, https://doi.org/10.1175/15200469(2000)057<2989:AIOIPM>2.0.CO;2.

Phillips, V. T. J., A. M. Blyth, P. R. A. Brown, T. W. Choularton, and J. Latham, 2001: The glaciation of a cumulus cloud over New Mexico. Quart. J. Roy. Meteor. Soc., 127, 1513-1534, https://doi.org/10.1002/qj.49712757503.

Plummer, D. M., and Coauthors, 2018: Radar-derived structural and precipitation characteristics of $Z_{\mathrm{DR}}$ columns within warm-season convection over the United Kingdom. J. Appl. Meteor. Climatol., https://doi.org/10.1175/JAMCD-17-0134.1, in press.

Pruppacher, H. R., and J. D. Klett, 2010: Microphysics of Clouds and Precipitation. 2nd ed. Springer Netherlands, 954 pp.

Rogers, R. R., and M. K. Yau, 1989: A Short Course in Cloud Physics. 3rd ed. Elsevier, 304 pp.

Sun, J., P. A. Ariya, H. G. Leighton, and M. K. Yau, 2010: Mystery of ice multiplication in warm-based precipitating shallow cumulus clouds. Geophys. Res. Lett., 37, L10802, https://doi.org/ 10.1029/2010GL042440.

Taylor, J. W., and Coauthors, 2016a: Aerosol measurements during COPE: Composition, size, and sources of CCN and INPs at the interface between marine and terrestrial influences. Atmos. 
Chem. Phys., 16, 11 687-11 709, https://doi.org/10.5194/acp-1611687-2016.

_ , and Coauthors, 2016b: Observations of cloud microphysics and ice formation during COPE. Atmos. Chem. Phys., 16, 799826, https://doi.org/10.5194/acp-16-799-2016.

Yuter, S. E., and R. A. Houze Jr., 1995: Three-dimensional kinematic and microphysical evolution of Florida cumulonimbus. Part II: Frequency distributions of vertical velocity, reflectivity, and differential reflectivity. Mon. Wea. Rev., 123, 1941-1963, https://doi.org/10.1175/1520-0493(1995)123<1941: TDKAME $>2.0 . \mathrm{CO} ; 2$.

Ziegler, C., 1985: Retrieval of thermal and microphysical variables in observed convective storms. Part 1: Model development and preliminary testing. J. Atmos. Sci., 42, 1487-1509, https://doi.org/10.1175/1520-0469(1985)042<1487: ROTAMV $>2.0 . C O ; 2$. 